Review

\title{
Poriferan Chitin as a Versatile Template for Extreme Biomimetics
}

\section{Marcin Wysokowski ${ }^{1 \dagger} \dagger *$, Iaroslav Petrenko ${ }^{2}$, Allison L. Stelling ${ }^{3}$, Dawid Stawski ${ }^{4}$, Teofil Jesionowski ${ }^{1}$ and Hermann Ehrlich ${ }^{2, \dagger}$}

1 Institute of Chemical Technology and Engineering, Faculty of Chemical Technology, Poznań University of Technology, Berdychowo 4, 60965 Poznań, Poland;

E-Mail: teofil.jesionowski@put.poznan.pl

2 Institute of Experimental Physics, Technische Universität Bergakademie Freiberg, Leipziger str. 23; 09596 Freiberg, Germany; E-Mails: iaroslavpetrenko@gmail.com (I.P.);

Hermann.Ehrlich@physik.tu-freiberg.de (H.E.)

3 Center for Material Genomics, Department of Mechanical Engineering and Materials Science, Duke University, 27708 Durham, NC, USA; E-Mail: antistokes@gmail.com

4 Department of Commodity and Material Sciences and Textile Metrology, Lodz University of Technology, Żeromskiego 116, 90924 Lódź, Poland;

E-Mail: dawid.stawski@p.lodz.pl

$\dagger$ These authors contributed equally to this work.

* Author to whom correspondence should be addressed; E-Mail: wysokowski@wp.pl; Tel.: +48-61-665-3626; Fax: +48-61-665-3649.

Academic Editor: Kjell M. Vårum

Received: 6 November 2014 / Accepted: 3 February 2015 / Published: 9 February 2015

\begin{abstract}
In this mini-review, we shall first cover a short history of the discovery of chitin isolated from sponges; as well as its evolutionarily ancient roots. Next, we will delve into the unique structural, mechanical, and thermal properties of this naturally occurring polymer to illuminate how its physicochemical properties may find uses in diverse areas of the material sciences. We show how the unique properties and morphology of sponge chitin renders it quite useful for the new route of "Extreme Biomimetics"; where high temperatures and pressures allow a range of interesting bioinorganic composite materials to be made. These new biomaterials have electrical, chemical, and material properties that have applications in water filtration, medicine, catalysis, and biosensing.
\end{abstract}


Keywords: chitin; sponges; extreme biomimetics; hydrothermal synthesis; scaffolds

\section{Introduction}

In recent years, there has been an increasing interest in biodegradable polymers isolated from sources found in Nature. These include polysaccharides, nucleic acids and peptides. The unique three dimensional, nano-organized scaffoldings of such polymers can yield desirable macro-physical attributes related to their mechanics, chemistry, and thermostability. It is well known that among polysaccharides, chitin is one of the most abundant biopolymers in the biosphere. Despite this fact and its earlier discovery, currently chitin is still under-investigated compared to the more abundant cellulose. The discovery of chitin's chemical identity and its polymeric properties took over 100 years- perhaps unsurprising, as the term "polymer" was not accepted until 1930 [1].

\subsection{Historical Landmarks in the Discovery of Chitin}

Chitin was first reported in 1811 by the French scientist Henri Braconnot, who discovered an alkali resistant fraction during his studies of higher fungi. This substance was likely a complex material; containing alkali resistant proteins, chitin, and other polysaccharides. Based on this discovery, he proposed the name fungine [1,2] for this isolated material. He additionally reported possible formation of acetic acid from this isolated fungine. However, in 1823 Odier isolated material with similar properties from beetle cuticles by treatment with hot $\mathrm{KOH}$ solutions [1,2]. Odier proposed the currently used name of chitin for this substance. He did not detect the presence of nitrogen, and compared the isolated material to lignin. Odier assumed that a similar material might be found within many insects and plants.

Odier's conclusion that insects and plants share a similar structural material was something of a sensation at the time. The resultant controversy prompted extensive studies on the chemical structure and composition of these isolated natural products. In 1824, the presence of nitrogen in chitin was reported by Children [2], and proved in 1843 by Payen [1]. This milestone was achieved by Ledderhose. After heating in concentrated $\mathrm{HCl}$ for $30 \mathrm{~min}$, Ledderhose identified acetic acid and glucosamine as the products of chitin hydrolysis. On the basis of Ledderhose's $[3,4]$ results, the name of glucosamine was coined by Tiemann (1884) [5-7]. Further analyses proved that the configuration at carbon atoms $\mathrm{C}(3)-\mathrm{C}(5)$ are the same, as is seen for (D)-glucose. It was also shown that the $-\mathrm{NH}$ group is at the $\mathrm{C}(2)$ position on the monosaccharide unit.

Stronger evidence for $\mathrm{N}$-acetylation in chitin was provided in 1902 by Fränkel and Kelly [8], who obtained $\mathrm{N}$-acetyl-D-glucosamine by gentle hydrolysis of chitin at room temperature using $70 \% \mathrm{H}_{2} \mathrm{SO}_{4}$. The products of the reaction were identical to those seen with synthetic $N$-acetylation of D-glucosamine. Similar observations were made by Karrer and Hofmann [9], who used enzymatic degradation to isolate $N$-acetyl-D-glucosamine from lobster shell and fungal chitin. These studies showed fungal and animal chitin had the same chemical composition [2]. The isolation of disaccharide and trisaccharide units were reported by Bergmann [10], and Zechmeister and Tóth [11], respectively. Their work proved that chitin is a polymer composed of $N$-acetyl-D-glucosamine units. Yet, how these units were bound together on a chemical level remained a question of much interest within the community at the time. 
The answer came by coupling information from studies on unsubstituted primary hydroxyl groups and the pyranose rings of sugar residues with X-ray diffraction studies performed by Meyer and Mark [12,13]. Highlighted above are a few historical milestones in the discovery of chitin's structure. A chronological and detailed historical background can be found in "Chitin Chemistry", a thorough book on the topic by Roberts [2].

\subsection{Discovery of Chitin in Sponges}

The great natural abundance of chitin arises from the broad range of species that use chitin as a structural component. These include yeast and fungi [14-18]; diatoms [19,20]; coralline alga [21], protists [22-24], corals [25]; mollusk [26-31], polychaetes [32,33]; spiders [34,35]; insects [36-38]; crustaceans including crabs [39-41], lobsters [42-44], shrimps [45,46], krill [47-49]. It has also been found within fish [50]. Surprisingly, until 2007, chitin had not been identified in sponges (Porifera). In 2007, the first reports on chitin in Verongida rigida marine demosponge skeletons were published by Ehrlich and co-workers [51]. These authors showed a remarkable similarity in structure between $\alpha$-chitin from other invertebrates, and chitin found in the fibers of the studied marine sponge. These results suggest that a chitin-production system is an ancestral feature in Metazoa. This implies the pathway for chitin synthesis may have evolved much earlier than previously thought.

Immediately after this discovery, Ehrlich and co-workers published the first report showing chitin is an endogenous material within the siliceous skeletons of glass sponges [52]. It was hypothesized [52] that the chitin molecule may be part of a very old template system involved in biosilicification phenomena; which was established long before the origin of glass sponges in the Cambrian period. In 2009, Brunner et al. [53] discovered that chitin-based scaffolds are an integral part of skeletons from the marine demosponge Ianthella basta of the Verongida order. This study showed how marine sponges can produce unique, chitin-based, highly organized two-dimensional networks composed of cross-linked fibers approximately $c a$. 40-100 nm in diameter. These fibers consist of loosely packed chitin; with rough, deeply fissured surfaces [53]. In the native sponge skeleton, proteins and bromotyrosine-related compounds are intercalated into the chitin-based scaffold and are cross-linked with the chitin, thus preventing it from forming unperturbed crystalline chitin [53].

Rohde and Schupp [54] demonstrated that I. basta, a marine sponge, is an organism capable of regenerating damaged chitin-containing tissue. It was found to have a reasonably rapid growth rate of $20 \mathrm{~cm} /$ year. It is thus quite feasible to grow or farm the amount of material needed for manufacturing from natural, renewable sources via marine ranching; or primmorph cultivation of sponges. In 2010, Ehrlich et al. [55] performed systematic chitin isolation studies on numerous representatives of the Aplysinidae family. The results revealed the presence of a chitin-based scaffold closely resembling the shape and morphology of the original sponge for all species studied. The presence of chitin in several specimens of the Aplysina genus from the Mexican Pacific, and in the Aplysina fistularis sponge skeleton, was confirmed in 2012 [56] and 2013 [57], respectively. In 2013, Ehrlich and co-workers published two papers detailing the discovery of chitin in skeletal structures of fresh water sponges like Lubomirskia baicalensis [58] and Spongilla lacustris [59]. These were the first reports that chitin identified within the holdfast of L. baicalensis plays a crucial role the sponge's adhesion to its rocky 
substrate [58]. Such discoveries of chitin within the skeletons of both marine and freshwater sponges can also yield information useful for classifying sponge species.

Intriguingly, the oldest chitin found in nature is also of sponge origin. Recently, Ehrlich and co-workers reported that fragments of chitin fibers survived in the 505 million year old (Middle Cambrian) Burgess Shale Vauxia gracilenta sponge fossils [60]. The chitin found in these Vauxia sponge fossils is thus far the oldest known to show this exceptional chitin preservation, compared to previously reported chitin fossils [61,62].

The tubular chitinous scaffolds isolated from demosponges possess unique three dimensional, fibrilar morphology with numerous chambers, channels, and the ability to swell [63]. The intricate network of tubes and chambers acts like a capillary, and the swelling in these skeletons is the result of capillary action. This swelling and other properties make chitin-based scaffolds promising candidates for practical applications in biomedicine and tissue engineering [64-66]. Furthermore, chitin in sponges is known as a versatile template for biomineralization in both calcification and silicification reactions [67]. For example, recent reports with Verongida sponge scaffolds show the formation of multiphase, nanostructured silica-chitin-aragonite biocomposites [68]. The specific role of sponge chitin in controlling multiphase biomineralization reactions can provide many opportunities for biomimetic routes and the in vitro design of uniquely complex biomaterials [63].

\section{Structural Properties of Chitin}

A number of reviews have been published regarding chitin chemistry [69], solubility [70,71] and chitin applications in biotechnology [72], waste water treatment [73-75], enzyme immobilization [76] and in biomedicine [72,77,78]. We, therefore, decided to focus this review on the specific properties of chitin that render it suitable for use in the more modern field of biomimetics, with a particular emphasis on extreme biomimetics.

Depending on its source, chitin occurs as two main polymorphs [79], namely the $\alpha$ - and $\beta$ - forms. Both forms can be differentiated by infrared; solid-state NMR [80] spectroscopy, and X-ray diffraction [81-83]. A third allomorph, $\gamma$-chitin, has also been described [84]. $\alpha$-Polymorph (Figure 1) has been the subject of intensive crystallographic research since 1920 [2]. Early published works established the unit cell dimensions, and probable space group [2]. A detailed model for the crystal structure of the fibrous polysaccharide $\alpha$-chitin was first proposed by Calström in 1957 [85]. He agreed with the previous assumptions of Meyer and Pankow that the orthorhombic unit cell containing chitobiose units run in opposite directions with the planes of the pyranose rings perpendicular to the a axis. However, he obtained different dimensions of unit cells ( $a=4.76 \AA, b=10.28 \AA$ and $c=18.85 \AA)$ and also indicated the space group was $\mathrm{P} 22{ }_{1} 2_{1}$ or $\mathrm{P} 22_{1} 2_{1}$ [85]. The main difference in the structure proposed by Calström, in comparison with previous assumptions (made based upon that of cellulose) was that the chitin chain cannot be considered as a straight line, which was thought unlikely owing to steric hindrance factors. Additional confirmations of the "bent chain" theory came from the $\mathrm{C}(3)-\mathrm{OH} \cdots \mathrm{O}(5)$ distance equal to $2.68 \AA$, an acceptable glycosidic bond $\left(107^{\circ}\right)$ and $a b$ repeating distance $10.28 \AA$. Additionally, in his model Calström took under consideration the $-\mathrm{NHC}(\mathrm{O}) \mathrm{CH}_{3}$ groups. He proposed planarity of the aminoacetyl groups and additionally concluded that because of the limited rotation of $\mathrm{C}(2)-\mathrm{N}$ the $\mathrm{N}-\mathrm{H}$ group has to point approximately towards the carbonyl oxygen of an adjacent chain in the $\alpha$ axis 
direction [85]. Strong evidence for an interchain hydrogen bond in this direction came from the distance of $2.69 \AA$ for the $\mathrm{C}(2)-\mathrm{NH} \cdots \mathrm{O}=\mathrm{C}(7)$ length. This model proposed by Calström was without doubt a milestone in determination of $\alpha$-chitin structure. However, it had still flagrant deficiencies. One of the critical remarks was that Calström's model suggested that $-\mathrm{C}(6) \mathrm{OH}$ are not involved in formation of hydrogen bonds, and a second was that the splitting of I amide band cannot be arranged in the same environment. Moreover, Calström had not included formation of interchain hydrogen bonds in the direction of $c$-axis, which is surprising as the $\alpha$-chitin does not swell in water $[2,86]$. Minke and Blackwell, in their fundamental work, applied the least-squares refinement of X-ray diffraction using models with P2 12121 symmetry. In their refined a model, that assumed antiparallel organization of chains, they demonstrated the formation of both intramolecular hydrogen bonds $\mathrm{C}(6) \mathrm{OH} \cdots \mathrm{O}=\mathrm{C}(7)$ in one chain as well as intermolecular hydrogen bonds $\mathrm{C}(6) \mathrm{OH} \cdots \mathrm{HOC}(6)$ between two chains. As a result, the proposed structure contains two type of amide groups, which differ in their hydrogen bonding environments; explaining the splitting of the I amide band in the IR spectra of $\alpha$-chitin. Although this $\alpha$-chitin model proposed by Minke and Blackwell is commonly accepted, it still remains a topic of extensive of experimental $[81,87]$ and theoretical ab initio studies [88]. These studies gave evidence of intermolecular hydrogen bonds in the G-G+ conformations [88] and formation of special hydrogen bond networks [81].

The earliest model for $\beta$-chitin structure was proposed by Dweltz [89] when he determined the P 21 space group. Additionally, he identified that the $-\mathrm{NH}$ groups are involved in formation of intermolecular hydrogen bonds along the $a$ axis; and additionally proposed formation of intermolecular hydrogen bonding through water molecules in the $c$ axis [89,90]. It has also been identified that the unit cell in $\beta$-chitin is monoclinic [89,90], and adjacent sheets along the $c$ axis have the same direction. It should be noted that in this polymorph we observe a lack of hydrogen bonds along the $b$ axis, which make it more susceptible for intra-crystalline water swelling in comparison to $\alpha$-chitin [91,92]. The swelling phenomenon takes place without destruction of the initial microfibrillar morphology, which can be recovered after removal of the intra-crystalline quest molecules [93]. These properties suggest that native $\beta$-chitin usually occurs in a hydrated form, because it is synthesized by living organisms under water. Kobayashi [94] et al. studied the crystal transition between hydrated and anhydrous $\beta$-chitin isolated from (Lamellibrachia satsuma) with synchrotron X-ray fiber diffraction. They showed that native $\beta$-chitin is in a dihydrate form. They also showed that it is not possible to return from anhydrate to the initial dehydrate form, even when the relative humidity is $100 \%$. Recently, Sawada et al $[95,96]$ provided a wealth of new information on the interaction of $\beta$-chitin with solvents. By application of the high-resolution $\mathrm{X}$-ray and neutron fiber diffraction studies these authors showed that the complexed molecules (like water and ethylenediamine) interact with side groups and change the conformation and H-bonding systems within $\beta$-chitin structure. The common effect of water and ethylenediamine is to disrupt the $\mathrm{O}(3) \cdots \mathrm{O}(5)$ intramolecular $\mathrm{H}$-bond and change the conformation of the $\mathrm{C}(6)-\mathrm{OH}$ group [95].

For the first time, the presence of a third, very rare polymorph of chitin was reported by Rudall [83]. The most recent studies published by Jang [84] showed the XRD pattern of $\gamma$-chitin with maximum peaks around $2 \Theta=9.6^{\circ}$ and $2 \Theta=19.8^{\circ}$ which means that $\gamma$-chitin, with an antiparallel and parallel structure, close in its XRD patterns to $\alpha$-chitin.

It has been suggested $[2,83]$ that the chitin polymorphs are related to the diversity of their functions. $\alpha$-Chitin is mainly found in organisms where extreme mechanical properties are required (hardness) and 
it is commonly associated with inorganic compounds [67]. The best example of this phenomenon is the dactyl club of the Mantis shrimp, where a $\alpha$-chitin template is mineralized in the exocuticle by an oriented crystalline hydroxyapatite. This forms the Bouligand-type structure, and as a result, the stomatopod's club is able to withstand multiple high-energy impacts [97]. Similar phenomenon has been noticed for lobsters of Homarus americanus, where the exoskeleton is a multilayered composite tissue consisting of crystalline chitin and various types of proteins. Raabe et al. [98] indicated that in lobster cuticle chitin chains are arranged in an antiparallel fashion forming $\alpha$-chitin, which in turn form nanofibrils assembled into honeycomb shaped arrays. These are stacked along their normal direction of about $180^{\circ}$ and referred to as the plywood or Bouligand layer. Synchrotron wide angle diffraction analysis showed that samples taken from different parts of the exoskeleton revealed a similar crystallographic texture, indicating that the $\alpha$-chitin has a very similar orientation along the entire cuticle surface. This, together with the "mechanical selection theory", encouraged Raabe and co-workers [98] to hypothesize that the $\alpha$-chitin matrix relative to the local sample coordinates turns out to be mechanically favorable, providing maximum protection. Ehrlich et al. [59] also showed that incorporation of $\alpha$-chitin into proteinaceous skeletons of fresh water sponge (Spongilla lacustris) appears to be selectively favored because the resulting material becomes more rigid. Moreover, $\alpha$-chitin identified within the holdfast of endemic freshwater sponge Lubomirska baicalensis plays a major role in the adhesion of sponges to rocky substrate [68].

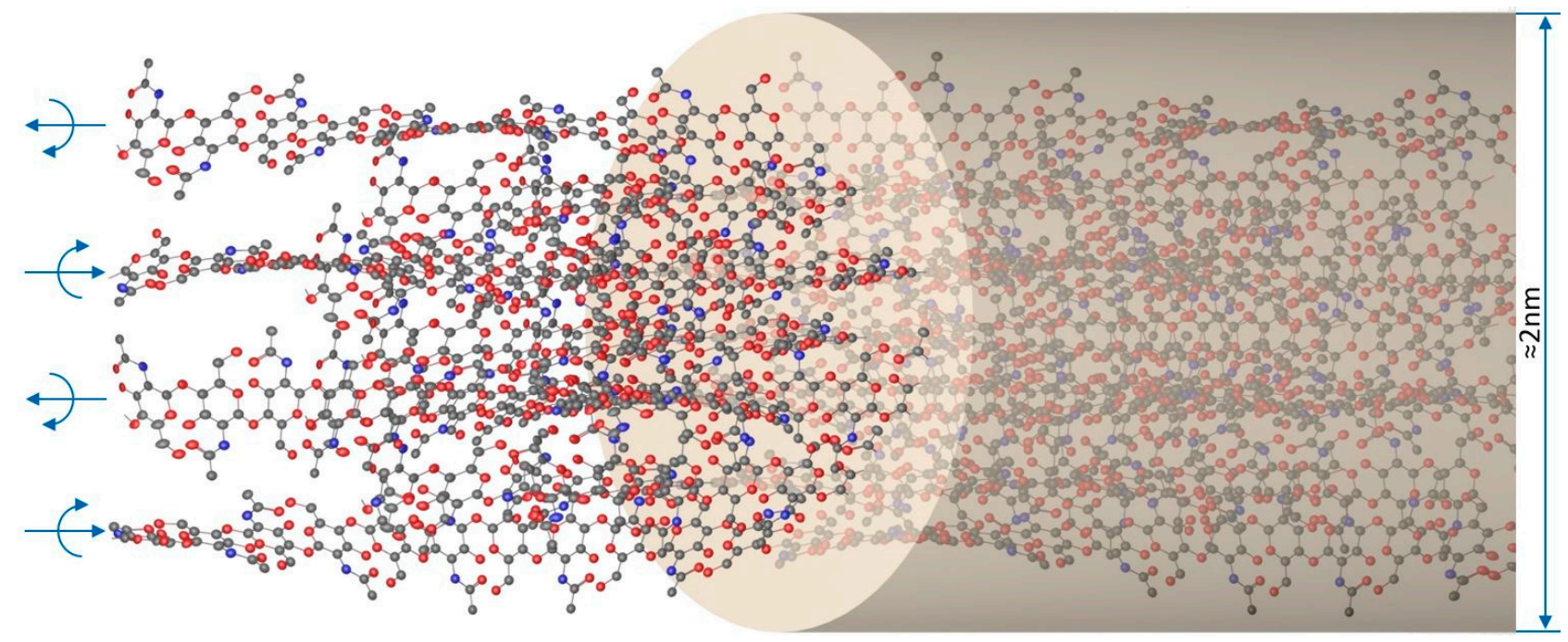

Figure 1. A schematic view of an alpha chitin nanofiber structure.

In contrast, $\beta$-chitins are usually found in organisms where both flexibility and toughness are required [2]; for example in squid pens [99] or tube worms [33]. Interestingly, all three polymorphs has been indicated within different parts of the Loligo sp. squid pen $(\alpha$-chitin in thin cuticle lining stomach, $\beta$-chitin in pen, $\gamma$-chitin in thick cuticle lining stomach) and in some insect cuticles [83]. This phenomenon indicates that different forms are related to their function, rather than to taxonomic grouping $[2,83]$.

The chitin isomorphs isolated so far from arthropods (crabs, lobsters, shrimps, crayfish, king crabs and insects) as well as mollusks (e.g., squids) occur in the form of granules, sheets or powder - not as 2D or 3D scaffolds. As most chitin derived from marine organisms is biocompatible, there is a strong incentive for using this material as a scaffolding for tissue cells. The present generation of materials for 
structural supports in tissue engineering is based on seeding cells onto porous biodegradable polymer matrices. A primary factor is the availability of these biomaterials to serve as a temporary matrix. It is crucial to prepare these scaffolds in porous sponge-like forms on a cellular spatial scale, offering microscale channels for the migration of host cells and nutrients into the matrix. The biomaterials must also permit growth into complete, macroscale tissue analogues and be degradable into non-toxic products once they have served their function in vivo [63]. There is a dearth of "prefabricated" natural 3D chitin scaffolds, as such structures are complex to create via purely synthetic routs and difficult to isolate from natural source material.

Several attempts have been made to process chitin into 3D nanoporous materials for potential applications in tissue engineering. One of the most popular ways to prepare chitin or chitosan for cell seeding is to first make a precursor, typically a gel, followed by various lyophilization strategies. For example, Abe et al. [100] developed a freeze-drying method for production of a bioresorbable $\beta$-chitin sponge as the scaffold for culturing chondrocytes. The resulting material was a cartilage-scaffold composite with a biodegradable cartilage-like layer at the surface. Okamoto et al. [101] successfully applied chitin-sponges in veterinary practice, using them as a filling agent for surgical tissue defects. For a thorough review of the biomedical applications of chitin biomaterials with sponge-like morphology, we would recommend reading paper written by Shigemasa and Minami [102].

Sponge-like chitin materials have also exhibited other intriguing physicochemical properties. They are highly effective for oil separations, which may be useful for containing spills or leaks into the environment. This property arises from the existence of the hydrophilic hydroxyls and acetyl amino group, combined with hydrophobic pyranose rings on the chitin molecules. These balance to give the overall material amphilicity, and allows uptake of both polar and nonpolar liquids [103]. Chitin sponges prepared by freeze-drying methods exhibited many remarkable properties, including very low density, high porosity, good mechanical properties and excellent oil absorption performance.

These studies indicated that the development of environmentally suitable technologies for chitin dissolution, or to process chitin into sponge-like morphologies, is still of huge interest. A number of such studies have already sought to optimize the reaction using specific solvents (e.g., ionic liquids [104-106]) or deep eutectic solvents [107]. These allow the chitin to dissolve and facilitate processing chitin into sponge-like structures, membranes or fibers. However, most of these procedures are unattractive from an economic standpoint.

A breakthrough was reported by professor Ifuku and his research group [108-110]. They proposed a simple, mechanical grinding method for processing chitin into uniform nanofibers (10-20 nm width). The advantage of this technology is that it is cost effective and can be performed on a large scale. $\mathrm{Lu}$ et al. [111] have proposed another facile route for processing chitin into nanofibers. They use $\alpha$-chitin nanofibers fabricated from dried shrimp shells via a simple high-intensity ultrasonic treatment under neutral conditions. The ultrasonication breaks the micro-scale fibers into nanofibers in water, in a process based on cavitation. The shockwaves caused by the implosion of the cavity can break the chitin interfibrillar hydrogen bonding and the Van der Waals forces. The advantage of this technology is that the diameter of the chitin nanofiber products could be controlled within 20-200 nm simply by adjusting the ultrasonication time. However, processing nanofibers into sponge-like, 3D structures still has an additional step — commonly by lyophilization. 
Isolation of morphologically defined two-dimensional or three-dimensional chitin structures pre-formed in sponges overcomes several technical limitations associated with manufacturing chitin into desired structures. Therefore, it is highly cost-effective and efficient, and aligns closely with "green chemistry" concepts. Sponge-derived chitin is therefore poised to make deep inroads within bioinspired materials science. "Prestructured" naturally occurring tube-like chitin-based scaffolds (Figure 2) have so far only been isolated from demosponges. Principally, a chitin molecule has $\mathrm{C}=\mathrm{O}, \mathrm{N}-\mathrm{H}$ and $\mathrm{O}-\mathrm{H}$ functional groups, resulting in an affinity for calcium phosphates, carbonates, and silicates [67,97,112,113]. Consequently, the unique nanofibrous architecture of chitin-based scaffolds isolated from sponges (Figure 3) can serve as a structural template for promoting biomimetic in vitro synthesis of numerous inorganic phases, both amorphous and crystalline, under selected conditions.
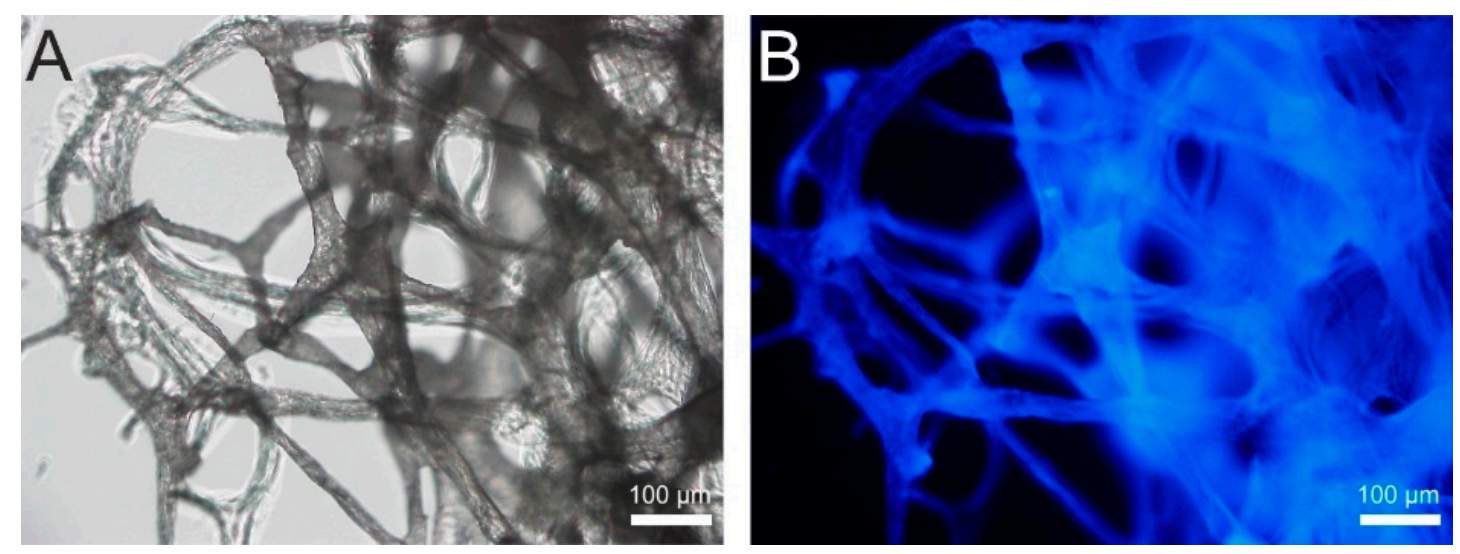

Figure 2. Typical three-dimensional fibrilar structure of chitin isolated from the skeleton of Aplysina aerophoba demosponge in (A) light microscopy and (B) fluorescent microscopy modus.

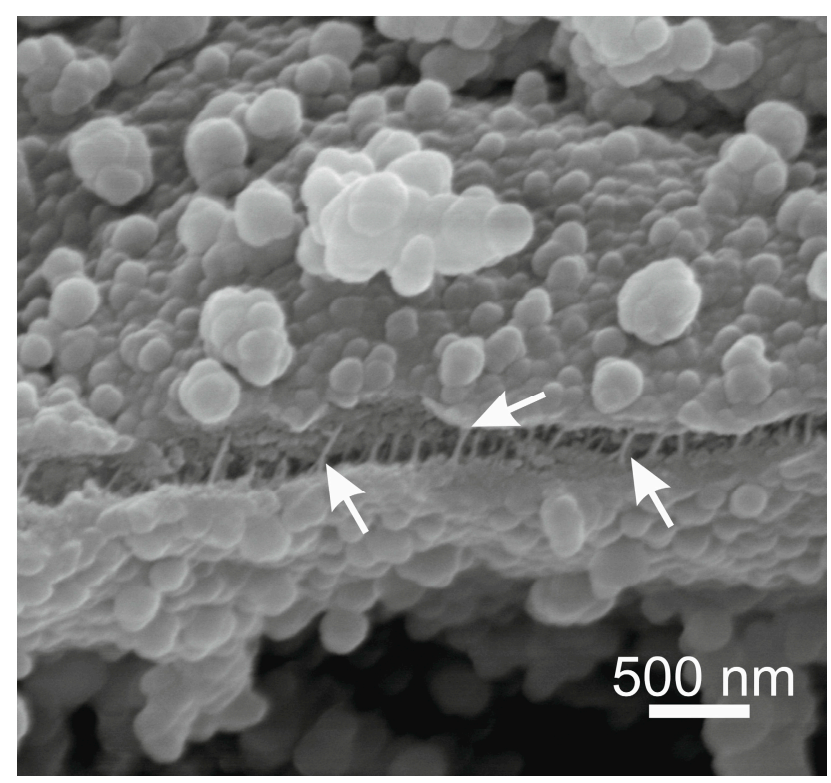

Figure 3. SEM (Scanning Electron Microscope) image of a microfracture on the surface of a chitin-silica composite obtained using hydrothermal conditions (for details see [114]). Due to this microfracture, the nanofibrillar organization of the chitinous matrix can be seen clearly (arrows). 


\section{Mechanical Stability of Chitin-Based Materials}

Chitin plays a major role in biological structural materials with significant physical attributes, such as lobster shells [44], the mineralized dactyl club of the stomatopods [97,112], diatoms cell [20], glass sponges [52], copepod teeth's [115], spider fangs [116] and nacre [117]. Surprisingly, the industrial uses of chitinous materials have been largely based on its chemical characteristics (e.g., high nitrogen content) and unique biological properties, rather than on its ability to form structural composites with novel mechanical properties [117]. However, in order for these unique properties of chitin to be exploited in specific fields like contact lens fabrication, bone substitutes, tubes for nerve regeneration or membranes for soft tissue engineering - the chitin-based materials need to have specific mechanical properties. Therefore, recently many attempts have been made to tune the mechanical properties of chitin-based materials for specific applications. Among the different strategies used for tuning the flexibility and rigidity of chitin, the most popular is chemical derivatization of this polymer. The drawback of chemical modification is that it incurs the use of extra reagents, creating extra technological steps in the production cycle which may introduce toxic residues into the final product [118]. Therefore, to take advantage of the mechanical characteristics of chitin, the product should be used directly without the need for chemical modification [69].

The research group of Professor Eugene Khor [118] found that the crystallinity and mechanical properties of chitin films are a function of the amount of shrinkage from gel to the final film. They stated that the main challenge in the preparation of flexible chitin films is to manage the coagulation and shrinkage process during the preparation of chitin materials so they retain flexibility, reduce dimension distortion, and provide superior mechanical integrity in the dry state [118]. They dissolved chitin in Dimethylacetamide-5\% $\mathrm{LiCl}$ solution at $0{ }^{\circ} \mathrm{C}$ and proposed the unique "cold press" method of drying to produce flexible, transparent, conformable strong chitin films (thickness 28-300 $\mu \mathrm{m}$ ). The Young modulus varied from 1240 to $3650 \mathrm{MPa}$ and tensile strength between 38 and $60 \mathrm{MPa}$; which are good parameters for wound dressing materials.

Recently, Duan et al. [119] proposed a method for preparing high strength chitin films that displayed gas-barrier properties. They successfully created transparent pure chitin films by dissolving chitin in $11 \mathrm{wt} \% \mathrm{NaOH}-4 \mathrm{wt} \%$ urea aqueous solvent at low temperature. The chitin films regenerated with organic coagulants. They possessed a homogeneous mesoporous structure, optical transmittance, and exhibited excellent tensile strength up to $111 \mathrm{MPa}$. The excellent mechanical properties combined with the good gas barrier properties of chitin may find many applications in the food packaging industry.

Hassanzadeh et al. [120] recently reported on the mechanical properties of self-assembled chitin nanofiber networks. These authors dissolved $\beta$-chitin in hexafluoroisopropanol, resulting in a kind of "chitin-ink" [120]. Building on studies performed by Khor [118], for nanofiber self-assembly they used cold processing drying, vacuum drying and vacuum-assisted filtration. They proved that the mechanical properties depend on the preparation method used to promote self-assembly. They obtained films with tensile strengths of $146.6,111.3,123.1 \mathrm{MPa}$, respectively.

Since chitin nanofibers have an antiparallel extended crystal structure, they have high mechanical strength and Young's modulus, which is even higher than $150 \mathrm{GPa}[110,121]$. Thus, chitin nanofibers and nanowhiskers have been applied as a useful reinforcing elements to improve the mechanical properties of acrylic resins [122], polylactide [123] and poly( $\varepsilon$-caprolactone) $[124,125]$. 
In conclusion, these previous works demonstrate that chitin has unique mechanical properties attractive for many practical applications. All of them also show that chitin can be used as a mechanically stable template for the deposition of various metal oxides.

\section{Thermal Stability of Chitin}

Thermal stability is a property describing the decomposition of materials during heating. The higher the temperature needed to decompose a material, the more thermally stable it is. It is a crucial parameter in materials engineering for nearly all thermally mediated applications of biomaterials. These include thermal therapies (including cryosurgery), burn injury, biopreservation environments [126], and also the extreme processing of materials. Thermal methods, such as thermogravimetry (TGA), differential scanning calorimetry (DSC) and differential thermal analysis (DTA) are powerful thermal techniques for analysis of the thermal stability of various materials (natural and synthetic polymers [127], inorganic compounds as well as organic compounds) [128]. Therefore, with the development of new technologies for processing advanced chitin-based materials, and extreme biomimetics, it is crucial to know the thermal stability parameters of chitin. An analysis of the literature shows a few methods that have been widely used for monitoring thermal degradation in chitin and its derivatives.

Previously, Köll and Metzger [129,130] performed a thermogravimetric of chitin isolated from crab shells with an acetylation degree of $62 \%$. The degradation started at $200{ }^{\circ} \mathrm{C}$, and it was a two-step process. By on-line mass spectrometry, these authors confirmed that the first step is between 230 and $290^{\circ} \mathrm{C}$. It is mainly associated with formation of volatile acetamide compounds. However, the product after pyrolysis was not soluble in water. Therefore they stated that monomeric and oligomeric anhydrosugars are the primary degradation products of chitin. The observed two-step (characteristic for chitosan) degradation of the crab shell chitin was probably a result of its high degree of deacetylation during the analysis.

Wanjun et al. [131] applied the model-free iso-conversional method to evaluate the activation energies as a function of the extent of chitin degradation. Their results show that the activation energy of thermal degradation in chitin is constant at $223 \mathrm{~kJ} / \mathrm{mol}$. The constancy of the activation energy suggests that the degradation kinetics are essentially governed by a single reaction step; and this process follows a 1.23-order reaction. From the FTIR analysis of chitin before and after degradation these authors concluded that decomposition in chitin starts from the scission of the glycosidic bond at a weak point in the chitin backbone. There is then a subsequent depolymerization to monomers, followed by dehydratation of the pyranose ring and deacetylation [132].

Stolarek and Ledakowicz [133] claimed that when the reaction mechanism of chitin pyrolysis is unknown, Kissinger's method, used for determination of kinetic parameters in a standard procedure [133], can prove to be unreliable. Contrary to Kissinger's method that applies only one point on the DTG (derivative thermogravimetric) curve, Stolarek and Ledakowicz assessed kinetic models of chitin pyrolysis by a non-linear regression method that makes use of all points on the TG or DTG curve. They stated that the maximum rate of chitin decomposition occurs between 350 and $380^{\circ} \mathrm{C}$.

Nam et al. [134] compared the thermal decomposition of chitin and chitosan nanofibers. They proved that thermal decomposition of the chitin nanofibers occurred in a single step, whereas the chitosan nanofibers with a deacetylation degree (DD) $>50 \%$ showed a two-step degradation mechanism. In their 
comparative study on DSC curves they observed separate decomposition of glucosamine (GlcN) and $N$-acetyl-D-glucosamine (GlcNAc) units. This is a result of the higher thermal stability of the GlcNAc units. The study clearly showed that the maximum decomposition temperature of the chitin nanofibers is higher than that of the chitosan nanofibers. Additionally, by calculating the activation energy of the thermal degradation using the Horowitz and Metzger method, they proved the activation energy $(\sim 87 \mathrm{~kJ} / \mathrm{mol})$ of the chitin nanofibers was much higher than those $(\sim 35 \mathrm{~kJ} / \mathrm{mol})$ of the chitosan nanofibers.

Stawski et al. [49] in their work compared the thermal properties of chitins from different marine sources using a thermogravimetric technique. They showed that thermal resistance depends on the source used, and can be arranged as follows: krill chitin $>$ shrimp chitin $>$ crab chitin $>$ squid chitin. It was found that the monoclinic $\beta$-chitin obtained from squid is thermally much less stable than the orthorhombic $\alpha$-chitins originating from krill, crab and shrimp. These differences are easily explained by the different crystal structures, and the different orientation of chains. However, finding an explanation for differences in thermal stability in $\alpha$-chitin from different sources is a more challenging task. Stawski et al. [49] showed that the size and perfection of crystallites are the most important factors influencing the thermal stability of $\alpha$-chitin. It has been confirmed by FTIR (Fourier transform infrared spectroscopy) that sponge chitin is stable at $300^{\circ} \mathrm{C}$, even after $24 \mathrm{~h}$ of heating [60].

All the studies mentioned above were performed in an inert atmosphere (nitrogen or argon) to avoid a repolymerization and transport processes, which can obscure the primary solid-phase decomposition reactions. However, recently Gerogieva et al. [135] published an outstanding analysis of chitin thermal degradation in an oxidizing atmosphere. They performed thermogravimetric studies of chitin in an air atmosphere carried out using six rates for the linear increase in temperature. Moreover, these authors determined the kinetics for a mechanism of thermal decomposition using Kissinger-Akahira-Sunose's iso-conversional procedure; which is recommended by ICTAC kinetics committee. In an oxidizing atmosphere, thermal degradation of chitin starts at about $235{ }^{\circ} \mathrm{C}$ and ends at $510{ }^{\circ} \mathrm{C}$. This was due to vaporization- burning of volatile compounds produced from the exothermic depolymerization of chitin, and the formation of volatile low molecular products. These are burned in the oxidative atmosphere.

The thermal stability of chitins from different sources has been accumulated from the references summarized in Table 1. Most of the aforementioned studies proved that chitin is thermally stable up to $200{ }^{\circ} \mathrm{C}$. This thermal property is the driving force for developing new chitin-based materials and chitin processing routes at high temperatures using the principles of hydrothermal synthesis and extreme biomimetics.

Table 1. Comparison of thermal stability for chitins from different sources.

\begin{tabular}{cccc}
\hline Chitin Source & Thermal Degradation $\left({ }^{\circ} \mathbf{C}\right)$ & Atmosphere & Ref. \\
\hline unknown & $287-427$ & Inert & {$[131]$} \\
krill $(\alpha$-chitin $)$ & $250-410$ & Inert & {$[133]$} \\
crab shells $(\alpha$-chitin) & $220-400$ & Inert & {$[130]$} \\
regenerated chitin - from crab shells $(\alpha$-chitin) & $260-435$ & Inert & {$[136]$} \\
Euphausia superba krill $(\alpha$-chitin $)$ & $320-460$ & Inert & {$[49]$} \\
shrimp shells $(\alpha$-chitin) & $290-440$ & Inert & {$[49]$} \\
crab shells $(\alpha-$ chitin $)$ & $285-450$ & Inert & {$[49]$} \\
squid $(\beta$-chitin) & $210-400$ & Inert & {$[49]$} \\
Ianthella basta marine sponge $(\alpha$-chitin) & $325-530$ & Inert & {$[114]$} \\
\hline
\end{tabular}


Table 1. Cont.

\begin{tabular}{cccc}
\hline Chitin Source & Thermal Degradation $\left({ }^{\circ} \mathbf{C}\right)$ & Atmosphere & Ref. \\
\hline Aplysina cauliformis marine sponge $(\alpha$-chitin) & $300-420$ & Inert & {$[137]$} \\
crab shells $(\alpha$-chitin) & $290-400$ & Inert & {$[84]$} \\
crab shells $(\alpha$-chitin) & $300-410$ & Inert & {$[84]$} \\
Loligo pealeii squid $(\beta$-chitin $)$ & $260-370$ & Inert & {$[84]$} \\
Squid $(\gamma$-chitin) & $200-370$ & Inert & {$[84]$} \\
crab shells $(\alpha$-chitin) & $235-570$ & oxidizing & {$[135]$} \\
Oedipoda miniata orthoptera $(\alpha$-chitin) & $280-405$ & Inert & {$[138]$} \\
Geolycosa vultuosa Hogna radiata spiders $(\alpha$-chitin) & $275-400$ & inert & {$[35]$} \\
Chelonibia patula $(\alpha$-chitin) & $180-600$ & Inert & {$[139]$} \\
\hline
\end{tabular}

\section{Chitin and Extreme Biomimetics}

A biomimetic and bio-inspired approach for the synthesis of materials is a scientific and technological challenge that has been vigorously investigated in recent years [140-146]. There is interest in their nanoscale size, unique morphology, and properties which allow applications in biomedicine [140,141,144], as biosensors [140], and for catalysis [145,146]. In particular, the 2D and 3D nanostructural biocomposite-based scaffolds are crucial for a broad variety of advanced applications [147,148]. Biomimetic synthesis of materials is carried out with various biomolecules; especially enzymes [146], proteins $[149,150]$ peptides [151,152] and polysaccharides [153-157]. These biomacromolecules play an important role in nucleation, thermodynamic and kinetic control of crystal growth, and also can be used as soft templates for inorganic structures [143]. However, traditionally, approaches related to the in vitro biomimetic mineralization of organic templates are carried out at temperatures between 20 and $37^{\circ} \mathrm{C}$ and at near-neutral $\mathrm{pH}$ [149-158]. It is assumed that biological materials, especially protein-based ones, are not stable at temperatures higher than $40{ }^{\circ} \mathrm{C}$. Yet there are naturally occurring environments where life is found even at extremes of heat and pressure. These niches are still not fully investigated, and are typically aquatic hydrothermal environments with extreme physicochemical and thermal conditions. In these extreme niches numerous taxa of microorganisms, algae and invertebrates dwell in, as well as produce, biological materials with unique properties to withstand their environmental conditions. These may become an inspirational source for ideas in the development of biomimetic synthesis routes for making novel biomaterials.

Extreme Biomimetics is a newly established scientific direction proposed by our group that is focused on mimicking extreme environments for the development of a new generation of biomaterials and composites [114,137,159-161].

\subsection{Hydrothermal Vents and Hot Springs as a Source of Inspiration}

Hydrothermal vents are considered to be one of the most extreme environments on Earth. They are formed when water heated in Earth's crust by magma is forced explosively to the surface through rock fissures in volcanic regions [162]. Hot fluids, exiting vents at $400{ }^{\circ} \mathrm{C}$, are enriched with metal ions including ions of aluminum, copper, cobalt, iron, lead, manganese, and zinc. The environment is also rich in dissolved silica, sulfides, and gases such as hydrogen and methane [162]. Deep-sea vent sites, 
in addition to extremely high temperatures, high pressure, and a complete absence of light, have extremely sharp chemical-, $\mathrm{pH}-$, and temperature gradients between vent fluids and the surrounding seawater. Yet, remarkably, they possess a variety of marine invertebrates and microbes [163-166] adapted to physical extremes under these very special environmental conditions $[162,166]$.

Therefore, these environments are new areas for determining the upper temperature limits of life [166]. Vent communities are dominated by arthropods (38.8\%), mollusks (28.6\%), and annelid worms (17.7\%), while cnidarians $(4.6 \%)$, chordates $(3.7 \%)$, and sponges $(1.9 \%)$ have a notable presence [162]. In a theory which assumes that hyperthermophily is the origin and earliest evolution of life, Islas et al. [167] suggest that deep-sea hydrothermal vents have existed throughout the history of the planet and have played a major role in shaping early environments. These authors stated that high salt concentrations in hydrothermal fluids protect DNA and RNA against heat-induced damage. This and other non-biological mechanisms, such as adsorption to minerals' surfaces and formation of clay-nucleic acid complexes, might have played a critical role in the preservation of organic components and genetic polymers in primitive environments with temperatures of up to $100^{\circ} \mathrm{C}$ [168].

Most research done thus far has focused on two chitin producing representatives of the hydrothermal vent fauna, the Alvinella and Riftia species. Pompeii worms (Alvinella pompejana) are capable of withstanding temperatures up to $105^{\circ} \mathrm{C}$. They inhabit the hottest part of the hydrothermal ecosystem, on the walls of chimney-like structures [168]. The A. pompejana, which arise under these extreme physicochemical conditions, have attracted the attention of materials scientists as the multilayered structural exoskeleton of this organism incorporates minerals (sulfates). The interesting fact is that the predominant mineral phase found at the outer tube of this organism is marcasite [169], while the zinc sulfide (wurzite) is always predominant at the inner surfaces and within the matrix of the tubes. Additionally, their skeletons are composed of an unusual collagen that is stable up to $45^{\circ} \mathrm{C}$.

In contrast to $A$. pompejana, chitin plays the main role in the survival of Ritifia, another species that lives in hydrothermal vents. In $R$. pachyptila many microfibrils or crystallites of $\beta$-chitin are embedded in parallel within a protein matrix, and together form flat ribbon like structures [33]. A stabilization process using the disulfide bonds of the protein-chitin link seems to be the basis of this interaction, rather than the crystalline form of the chitin. Because of the unique stability, both chitin-based and collagen-based structures of vestimentiferan origin as well as their sophisticated exoskeletons possess intriguing biomimetic potential. This can be very useful for developing new technological processes, and new biomaterials with tunable properties.

Another examples of thermally extreme environments are hot springs. It has been well recognized that thermophilic and hyperthermophilic microorganisms are widely distributed around geothermal and hydrothermal environments. The cell walls of microbes generally include polysaccharides and proteins, have an affinity for silica, and have polyamines to catalyze the polycondensation of silicic acid in water [168]. The large number of reactive groups, differing chemical compositions, structures and functionalities characteristic for polysaccharides make them common nucleating and templating agents in living cells [170-173]. It is reported that exopolysaccharides [174,175] of various gram positive and gram negative bacteria are able to capture $\mathrm{Fe}^{3+}$ ions from solution and induce extracellular precipitation of hematite $\left(\mathrm{Fe}_{2} \mathrm{O}_{3}\right)$.

The most common mineralization process in geothermal vents is silicification. It is well known that numerous thermophilic microorganisms as well as thermotolerant diatoms are involved in biosilicification 
under extreme, high temperature environmental conditions. The most common in hot springs $\left(50-96^{\circ} \mathrm{C}\right.$, pH 1-3) are the following species: Rhopalodia gibberula, Navicula cincta, Achnanthidium minutissimum, Gomphonema parvulum, Nitzschia amphibian, and Achnanthidium exiguum [168]. The discovery of chitinous networks within the siliceous cell walls of the diatom Thalassiosira pseudonana [20] suggests the existence of silica-chitin composites. In the case of thermotolerant diatoms, this could be also arise under extreme physicochemical conditions similar to those of hot springs.

\subsection{Hydrothermal Technology for Extreme Biomimetics}

In general, hydrothermal synthesis refers to those chemical reactions conducted in aqueous solution under high pressure and temperature conditions. This technique was developed to mimic the formation of rocks and minerals in Nature [176]. From the definition, hydrothermal synthesis is a process that utilizes homogenous or heterogeneous phase reactions in aqueous media at elevated temperature $\left(T>25^{\circ} \mathrm{C}\right)$ and pressure $(\sim 100 \mathrm{kPa})$ to crystallize anhydrous inorganic materials directly from solution [177]. Reactants used in hydrothermal synthesis are generally called precursors, which are administered in different forms; including solutions, gels, suspensions and colloids. In hydrothermal synthesis reactions, mostly inorganic or organic additives (so-called mineralizers) are used. Their function is to control $\mathrm{pH}$, or to promote solubility. Other additives, also organic or inorganic, serve other functions such as promoting particle dispersion; or controlling crystal morphology [178].

A significant number of chemical systems in the form of crystalline powders and films can be synthesized in a wide range of conditions - from ambient temperatures, to temperatures and pressures at $200{ }^{\circ} \mathrm{C}$ and $<1.5 \mathrm{MPa}$, respectively. Recent advances in hydrothermal solution chemistry allow the principles of thermodynamics, kinetics, and chemical energy to be exploited more readily. Rapid development has allowed the production of autoclaves equipped with stirrers, temperature controllers, pressure controllers, and $\mathrm{pH}$ controllers. Hydrothermal technology has evolved as a powerful tool in materials processing. Hydrothermal methods can generate everything from bulk single crystals to fine and ultrafine crystals, down to nanocrystals or nanoparticles [178]. Moreover, hydrothermal technology allows for the synthesis of crystalline phases under "mild" conditions; which is preferable from both economic and environmental standpoints [179].

The discovery of hydrothermal vents and hot springs has led to a new thinking in marine biology and geochemistry, and set a new trend in advanced materials processing [180]. It is hypothesized that rich chemical reactions occurred in the warm sea, and all microorganisms have high-temperature ancestors. Mounting evidence supports the model of a hydrothermal origin of life [167]. The most interesting research involves non-enzymatic hydrothermal syntheses, which incorporate inorganic into organic or biological species. These interesting reactions need to be explored further for a deeper understanding of life's evolution- as well as possible industrial applications [181].

A great variety of biomaterials can be fabricated under ambient conditions by employing these Nature inspired conditions. Yoshimura and Byrappa [180] proposed a new scientific pathway called Soft Solution Processing. This was focused on the implementation of polymer templates (synthetic polymers, for example, PTFE membranes) which can be used under ambient, near, or just above ambient conditions to prepare a wide range of materials. These include complex and high melting point materials. Hydrothermal technology is a well-known method for synthesis of various inorganic, crystalline 
nanoparticles. It can be used for mimicking the biomineralization processes found in hydrothermal vents and springs. Thus, Yoshimura and Byrappa extended Soft Solution Processing and used mild hydrothermal, or electrochemically-assisted hydrothermal methods. These reactions where used to fabricate functional hybrid ceramics based films; and patterning on a variety of synthetic organic or inorganic substrates, including porous substances. In particular, this direction is essential to the fabrication of nanostructures on flexible plastic substrates, as well as easy integration with organic optoelectronic device fabrication [176].

In accordance with Soft Solution Processing, an Extreme Biomimetic approach includes mimicking the biomineralization processes found in hydrothermal vents. Consequently, Extreme Biomimetics is based on utilization of specific thermostable polymers, found in hydrothermal deposits, in a broad variety of hydrothermal reactions for the in vitro preparation of inorganic-organic materials. These materials are similar to those found in the skeletons of unique animals that habituate within hydrothermal vents. Extreme Biomimetic approaches can additionally be an important source of information for finding answers to fundamental questions about the mechanisms and principles of the biomineralization processes in the extreme environments of early Earth. It is thus important to perform both the hydrothermal synthesis of various biomaterials and also the mathematical modeling of kinetics and thermodynamics governing these processes. It is a challenging task: hydrothermal growth of crystalline inorganic nanostructures depends on many variables; including temperature, concentration of precursors used, presence and type of biomacromolecules, solution $\mathrm{pH}$ value, and pressure [176,178,182,183]. Thus, in the absence of predictive models, the fundamental role of these parameters for crystallization kinetics of various compounds and formation of biomaterials must be empirically defined. Intelligent modeling of the biomolecule assisted hydrothermal reactions will give us insights into chemical rules and principles of Extreme Biomimetics. This will give us a unique opportunity for engineering and generating new biomaterials.

\subsection{Extreme Biomimetics: Development of Chitin-Based Inorganic-Organic Materials under Hydrothermal Conditions}

The discovery of chitinous networks within the cell walls of the diatom Thalassiosira pseudonana [20] suggests the existence of silica-chitin composites. Such biomineral composites may also form under extreme physicochemical conditions, similar to those of hot springs. Additionally, practically all representatives of metazoan extremophile fauna contain the aminopolysaccharide chitin as the main structural component of their skeletons. It has been reported that chitin is high in crystallinity in its natural form and does not dissolve into hot water; which usually leads to decomposition reactions such as hydrolysis, deacetylation and dehydration when hydrothermally processed [184]. We strongly believe that the unique thermal stability of chitin (up to $200{ }^{\circ} \mathrm{C}$, reported in Section 4) is a key property, which shows the utility of this biopolymer in wide range of hydrothermal synthesis reactions. Additionally, various functional groups ( $-\mathrm{OH}$ and $\mathrm{C}=\mathrm{O}$ and $-\mathrm{NH}$ ) in the chitin molecule can interact with a precursor solution by forming covalent bonds. They can also undergo chelation reactions of metal ions and form hybrid organic-inorganic materials under hydrothermal conditions. These stable biopolymers can also influence and control nucleation, crystal growth and morphology of the formed inorganic phase. 
The process of hydrothermal deposition of inorganic structures on chitinous templates is facile and may be done in relatively few steps, see Figure 4. It is worth noting that the specific tubular chitinous scaffold structures of poriferan origin are extremely sensitive to drying at room temperature. Drying results in the fibers collapsing, leading to degradation of the 3D morphology [185]. Consequently, drying has a negative influence on their adsorptive properties for a precursor of inorganic phase [160]. Thus, in all our studies, to prevent the loss of the 3D morphology, we squeezed the chitinous scaffolds between filter papers to remove excess of water. After this, our samples were immediately soaked in a solution of precursor, hermetically closed in an autoclave, heated to the desired temperature, and kept under autogenous pressure for a specific time.

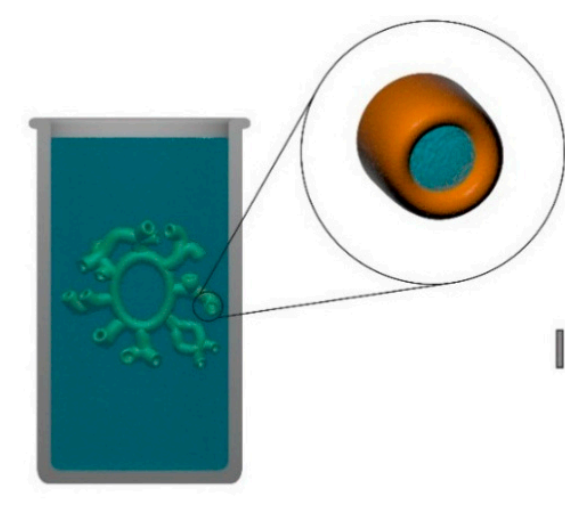

chitin scaffold swollen with water
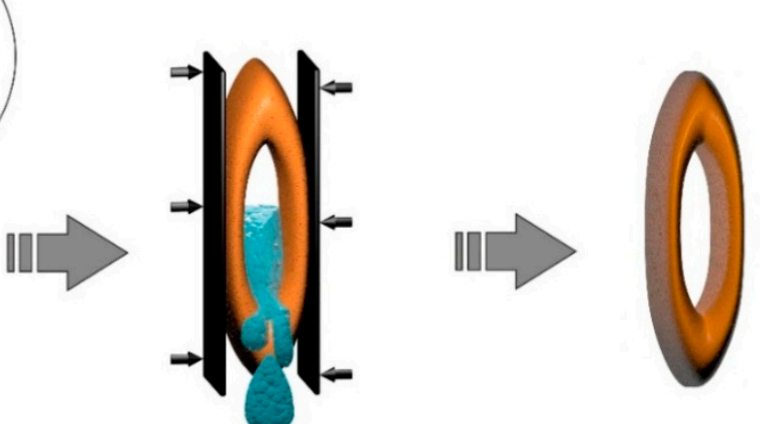

removal of water from

chitin tubes

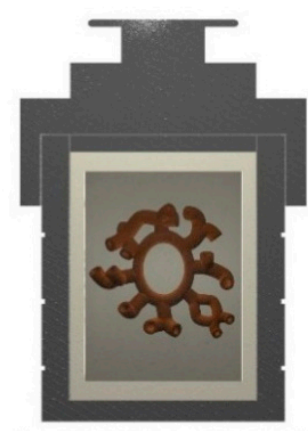

hydrothermal reaction in hermetically closed autoclave

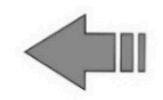

infiltration of precursor within chitin matrix (swelling) by squeezing

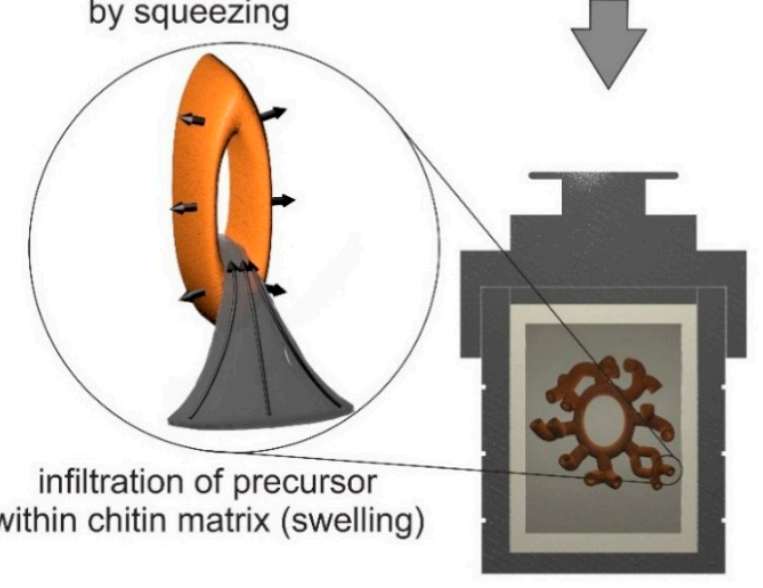

immersion of chitin in precursor solution

Figure 4. A schematic view for the exchange of different soaking solutions within the tubular $3 \mathrm{D}$ chitinous scaffold of sponge origin.

In our early work on Extreme Biomimetics, we decided to use chitin as a thermostable and versatile structural template for the hydrothermal deposition of silica nanoparticles from Stöber dispersions $[114,161]$. The results of this study showed the surprisingly thermostable two dimensional $\alpha$-chitin scaffolds isolated from skeletons of the marine sponge I. basta can be effectively silicified using a two-step method with Stöber silica dispersions and temperatures under $125{ }^{\circ} \mathrm{C}$. The silica-chitin composites obtained under hydrothermal conditions were characterized by the formation of a siliceous layer composed of uniform spherical silica nanoparticles on the chitin surface. It was also observed that 
nanosilica infiltrated into the nanoorgnized fibers of our chitin scaffold; this is marked by an arrow and can be easily seen in Figure 3. Analysis of FTIR and Raman spectra suggest that the chitin scaffold interacts with silica by hydrogen bond formation; especially at the $\mathrm{C}(6)$ position $[157,161,186]$. The results of the hydrothermal silicification of chitin open new possibilities for synthesis of chitin-silica composites, which gain particular interest in the development of bone substitutes for tissue engineering [77,187]; waste water treatment [188], and drug delivery systems [189].

The successful results of chitin silicification under hydrothermal conditions encouraged us to develop new chitin based materials by deposition of $\mathrm{ZrO}_{2}$ nanoparticles on chitin. Therefore, in our next study we decided to combine: (a) good reactivity of functional groups in the chitin molecule with ammonium zirconium carbonate (AZC) and (b) hydrothermal treatment, thus obtaining a new chitin-zirconia composite. For this purpose, we used three-dimensional chitinous scaffolds isolated from Aplysina aerophoba and Aplysina cauliformis sponges. The ammonium zirconium carbonate was chosen as the inorganic precursor for its good reactivity with carbohydrates [190,191]. The reaction was performed at $150{ }^{\circ} \mathrm{C}$. The products were thermos Table 3D $\alpha$-chitin scaffolds isolated from skeletons of the marine sponges A. aerophoba [160] and A. cauliformis [137], which were effectively mineralized with zirconia. The presented SEM images show the distribution of the zirconia particles with nanometric sizes on the surface of the sponge chitin fibers, see Figure 5.

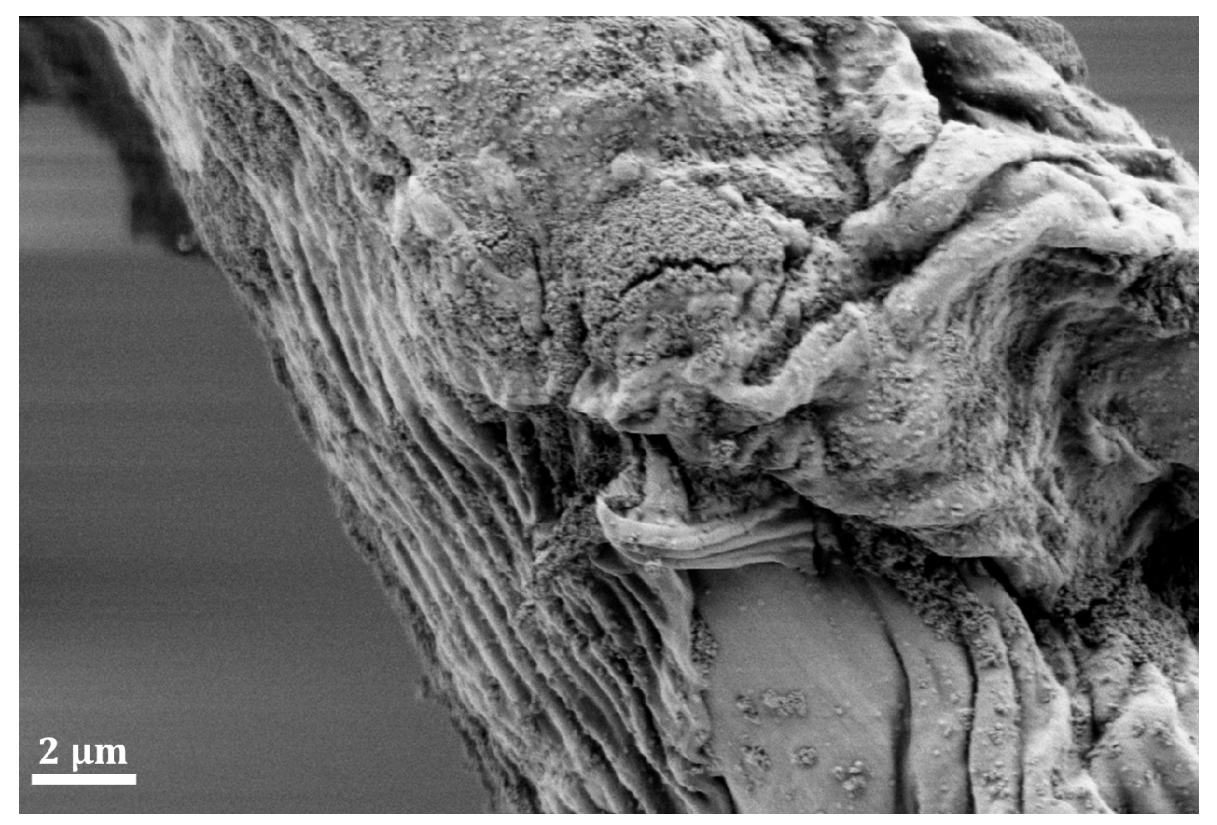

Figure 5. Hydrothermally obtained zirconia nanoparticles deposited on the surface of a chitinous template isolated from sponges. The inorganic particles form as huge conglomerates, as well as individual spherical nanoparticles.

Moreover, it was shown that deposition of zirconia occurs not only on the surface, but also within the chitin tubes [137]. Transmission electron microscopy as well XRD studies confirmed that zirconia deposited on chitin has monoclinic crystalline structure with crystallite sizes about $5 \mathrm{~nm}$ [125]. Analysis of the possible interactions between chitin and zirconia nanoparticles with Raman spectroscopy confirmed that formation of chitin- $\mathrm{ZrO}_{2}$ hybrid materials is due to hydrogen bond formation between chitin and $\mathrm{ZrO}_{2}[137,160]$. These chitin-zirconia composites are increasingly attractive for various 
applications, such as the construction of advanced zirconia-based hydrogen peroxide biosensors [192], adsorbents of heavy metals [193,194] and materials for biomedical devices [195-197].

Recently, we performed a synthesis of chitin/ZnO composites under mild hydrothermal conditions [159]. For this purpose, $\beta$-chitinous scaffolds isolated from the skeleton of marine cephalopod Sepia officinalis were used as a template for the in vitro formation of $\mathrm{ZnO}$ under conditions $\left(70{ }^{\circ} \mathrm{C}\right)$ which are extreme for biological materials. It was shown that chitin, similar to other polysaccharides, can interact with the positively charged (001) face of zincite crystals, and influence growth in the $c$-axis direction, see Figure 6. XRD (X-ray diffraction) and TEM (Transmission electron microscope) analyses confirmed that nanocrystals of $\mathrm{ZnO}$ grown in the presence of the chitinous template showed a characteristic hexagonal structure with a crystallite size of about $100 \mathrm{~nm}$. Moreover, it is important to add that the hydrothermally prepared chitin/ $\mathrm{ZnO}$ composites possess antibacterial properties against Gram positive bacteria, which gives them good prospects in the development of chitin based inorganic-organic wound dressing materials [159].

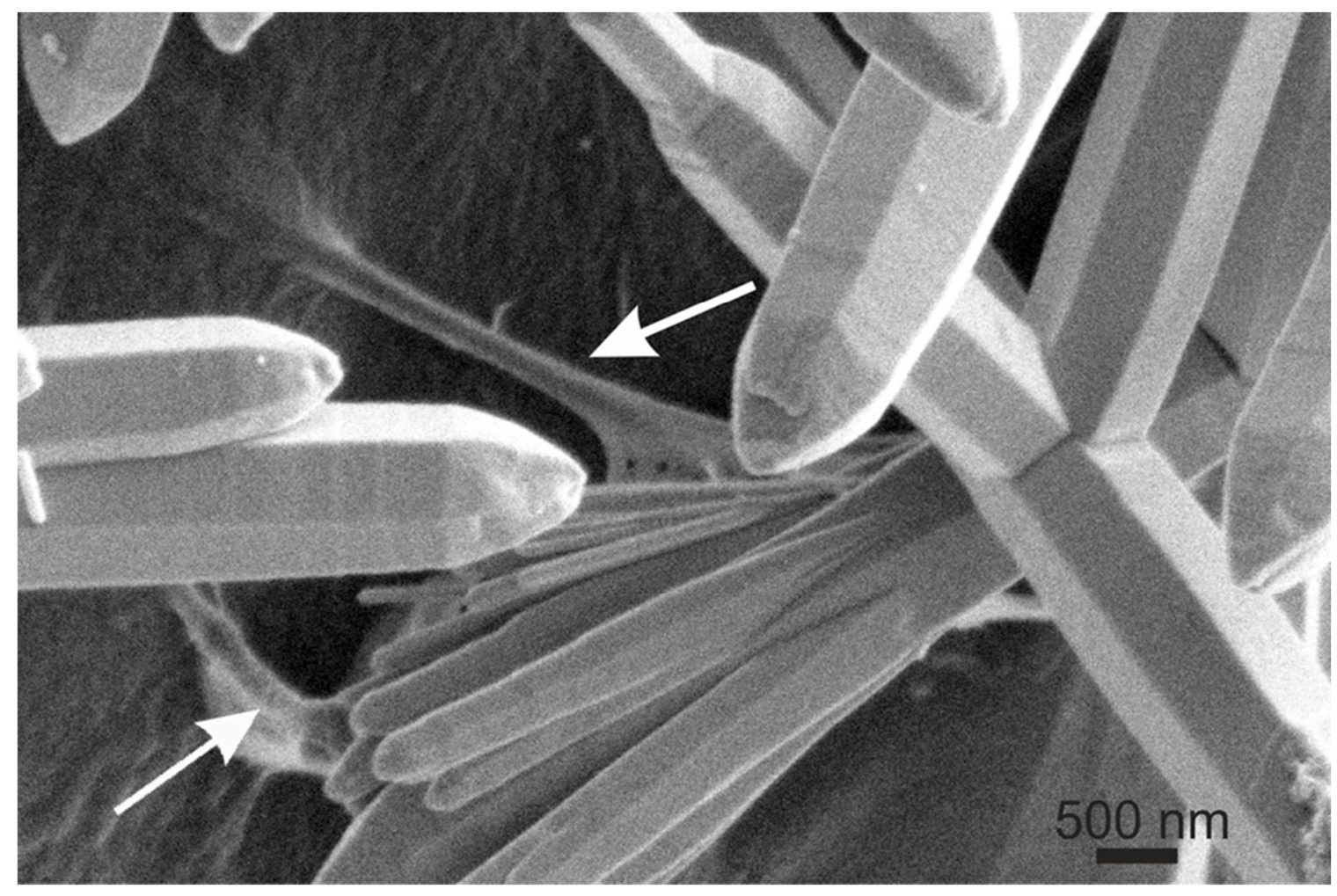

Figure 6. SEM image of the hydrothermally prepared $\beta$-chitin/ZnO composite. An arrow indicates the presence of $\beta$-chitin nanofibrils.

\section{Conclusions}

The recent observation of chitin-based scaffolds as an integral part of sponge skeletons suggests the presence of chitin several hundred million years before the appearance of this important biopolymer in arthropod skeletons. Chitin has also been discovered in freshwater sponges, such as S. lacustris and L. baikalensis. The presence of chitin in both marine and freshwater sponges indicates that this important structural biopolymer was already present in their common ancestor. Since 2007, we have succeeded in developing novel methods for the production two or three-dimensional cleaned chitin skeletons from 
dictyoceratid sponges, and the use thereof for synthetic reactions [198]. The discovery of chitin scaffolds as structural elements in the freshwater $S$. lacustris sponge skeleton offers many opportunities for novel practical applications. In addition to the well-known properties of chitin as a biomaterial and adsorbent, species of the suborder Spongillina are relatively easy to culture, and can regulate their growth. S. lacustris cultivation could provide a fruitful way to generate large amounts of chitin as a biomaterial in an environmentally sustainable fashion.

The biomimetic potential of chitin-based composite biomaterials of poriferan origin is analyzed in detail in a recently published monograph entitled "Biomimetic biomaterials: structure and applications" [57]. Furthermore, we show how sponge chitin can be used as a thermostable template for developing a new generation of biocomposites using "extreme biomimetic conditions" via a hydrothermal synthesis route (see for details $[114,137,159-161]$ ). We have also recently shown that sponge chitin can be successfully used for uranium adsorption from contaminated waste-waters [185].

Biomimetic synthesis is a driving force in engineering novel, advanced materials, which exhibit unique electronic, photonic, and catalytic properties. Morphologically defined biological architectures that incorporate inorganic nanocrystals are of fundamental interest for applications in bio-inspired materials science. Our results indicate that synthesis under extreme biomimetic conditions is a recently developed, powerful tool for the constructing various chitin-based hybrids. These inorganic-organic nanostructured composites can be made in the form of films, networks or scaffolds with special properties which arise from the inorganic phase. Recently, a hydrothermal route for processing chitin nanofibers into hydrogels was proposed by Nata et al. [199]. Combining this technology with Extreme Biomimetic concepts will pave the way for the development of diverse biomaterials.

We strongly hope that this article will encourage our scientific community to lend their attention to chitin, and view it as a novel source of nanoorganized naturally occurring templates for developing new materials and technologies using Extreme Biomimetics approaches.

\section{Acknowledgments}

This work was partially supported by Polish National Centre of Sciences research grant funds according to decision no. DEC-2012/07/N/ST8/03904; and following grants: Poznan University of Technology Research Grant No. 03/32/0506/2015-DS-PB; DAAD Section 323-Project No. 50015537; DFG Grant EH 394/3-1; BHMZ Programme of Erich-Krüger-Foundation (Germany) at TU Bergakademie Freiberg.

\section{Author Contributions}

Marcin Wysokowski-writing manuscript with regard to hydrothermal synthesis and Extreme Biomimetics; Iaroslav Petrenko-preparation of corresponding figures; Allison L. Stelling-brief history of chitin discovery; Dawid Stawski — description of chitin thermal properties; Teofil Jesionowski \& Hermann Ehrlich—supervising manuscript.

\section{Conflicts of Interest}

The authors declare no conflict of interest. 


\section{References}

1. Khor, E. Chitin: Fulfiling a Biomaterials Promise, 1st ed.; Elsevier Science Ltd.: Oxford, UK, 2001.

2. Roberts, G.A.F. Chitin Chemistry, 1st ed.; MacMillian: London, UK, 1992.

3. Ledderhose, G. Ueber salzsaures glycosamin. Ber. Dtsch. Chem. Ges. 1876, 9, 1200-1201. (In German)

4. Ledderhose, G. Ueber glykosamin. Z. Physiol. Chem. 1880, 4, 139-159. (In German)

5. Tiemann, F. Einiges über den abbau von salzsaurem glucosamin. Ber. Dtsch. Chem. Ges. 1884, 17, 241-251. (In German)

6. Tiemann, F. Ueber glucosamin. Ber. Dtsch. Chem. Ges. 1886, 19, 49-53. (In German)

7. Tiemann, F. Specifisches drehungsvermogen und krystallform des bromwasserstoffsauren Glucosamins. Ber. Dtsch. Chem. Ges. 1886, 19, 155-157. (In German)

8. Fränkel, S.; Kelly, A. Beiträge zur constitution des chitins. Monatsh. Chem. Verw. Teile Wiss. 1902, 23, 123-132. (In German)

9. Karrer, P.; Hofmann, A. Polysaccharide XXXIX. Über den enzymatischen abbau von chitin und chitosan I. Helv. Chim. Acta 1929, 12, 616-637. (In German)

10. Bergmann, M.; Zervas, L.; Silberkweit, E. Über chitin und chitobiose. Ber. Dtsch. Chem. Ges. 1931, 64, 2436-2440. (In German)

11. Zechmeister, L.; Tóth, G. Zur Kenntnis der hydrolyse von chitin mit salzsäure (I. Mitteil.). Ber. Dtsch. Chem. Ges. 1931, 64, 2028-2032. (In German)

12. Meyer, K.H.; Mark, H. Über den bau des krystallisierten anteils der cellulose. Ber. Dtsch. Chem. Ges. 1928, 61, 593-614. (In German)

13. Meyer, K.H.; Mark, H. Über den aufbau des chitins. Ber. Dtsch. Chem. Ges. 1928, 61, 1936-1939. (In German)

14. Garcia Mendoza, C.; Novaes Ledieu, M. Chitin in the new wall of regenerating protoplasts of Candida utilis. Nature 1968, 220, 1035.

15. Blumenthal, H.J.; Roseman, S. Quantitative estimation of chitin in fungi. J. Bacteriol. 1957, 74, $222-224$.

16. Elorza, M.V.; Rico, H.; Sentandreu, R. Calcofluor white alters the assembly of chitin fibrils in Saccharomyces cerevisiae and Candida albicans cells. J. Gen. Microbiol. 1983, 129, 1577-1582.

17. Peter, M.G. Chitin and chitosan in fungi. In Biopolymers Online; Steinbüchel, A., Ed.; John Wiley \& Sons: Weinheim, UK, 2005; pp. 123-132.

18. Muzzarelli, R.A.A.; Boudrant, J.; Meyer, D.; Manno, N.; DeMarchis, M.; Paoletti, M.G. Current views on fungal chitin/chitosan, human chitinases, food preservation, glucans, pectins and inulin: A tribute to Henri Braconnot, precursor of the carbohydrate polymers science, on the chitin bicentennial. Carbohydr. Polym. 2012, 87, 995-1012.

19. Durkin, C.A.; Mock, T.; Armbrust, E.V. Chitin in diatoms and its association with the cell wall. Eukaryot. Cell 2009, 8, 1038-1050.

20. Brunner, E.; Richthammer, P.; Ehrlich, H.; Paasch, S.; Simon, P.; Ueberlein, S.; van Pée, K.-H. Chitin-based organic networks: An integral part of cell wall biosilica in the diatom Thalassiosira. Pseudonana. Angew. Chem. Int. Ed. 2009, 48, 9724-9727. 
21. Rahman, M.A.; Halfar, J. First evidence of chitin in calcified coralline algae: New insights into the calcification process of Clathromorphum. Compact. Sci. Rep. 2014, 4, doi:10.1038/srep06162.

22. Cauchie, H.-M. Chitin production by arthropods in the hydrosphere. Hydrobiologia 2002, 470, 63-96.

23. Das, S.; Gillin, F.D. Chitin synthase in encysting Entamoeba Invadens. Biochem. J. 1991, 280, 641-647.

24. Campos-Góngora, E.; Ebert, F.; Willhoeft, U.; Said-Fernández, S.; Tannich, E. Characterization of chitin synthases from Entamoeba. Protist 2004, 155, 323-330.

25. Bo, M.; Bavestrello, G.; Kurek, D.; Paasch, S.; Brunner, E.; Born, R.; Galli, R.; Stelling, A.L.; Sivkov, V.N.; Petrova, O.V.; et al. Isolation and identification of chitin in the black coral Parantipathes larix (Anthozoa:Cnidaria). Int. J. Bol. Macromol. 2012, 51, 129-137.

26. Tóth, G.; Zechmeister, L. Chitin content of the mandible of the snail (Helix pomatia). Nature 1939, $144,1049$.

27. Goffinet, G.; Jeuniaux, C. Distribution et importance quantitative de u chitine dans les coquilles de mollusques. Cah. Biol. Mar. 1979, 20, 341-349. (In French)

28. Peters, W. Occurrence of chitin in mollusca. Comp. Biochem. Physiol. B 1972, 41, 541-544.

29. Weiss, I.M.; Schönitzer, V. The distribution of chitin in larval shells of the bivalve mollusk Mytilus galloprovincialis. J. Struct. Biol. 2006, 153, 264-277.

30. Winkler, L.R. Localization and proof of chitin in the opisthobranch mollusks Aplysia californica Cooper and Bulla gmtldiana (Pilsbry), with an enzymochromatographic method for chitin demonstration. Pac. Sci. 1960, 14, 304-307.

31. Weiss, I.M.; Schönitzer, V.; Eichner, N.; Sumper, M. The chitin synthase involved in marine bivalve mollusk shell formation contains a myosin domain. FEBS Lett. 2006, 580, 1846-1852.

32. Brunet, P.C.J.; Carlisle, D.B. Chitin in Pogonophora. Nature 1958, 182, 1689.

33. Gaill, F.; Shillito, B.; Lechaire, J.P.; Chanzy, H.; Goffinet, G. The chitin secreting system from deep sea hydrothermal vent worms. Biol. Cell 1992, 76, 201-204.

34. Krishnan, G.; Ramachandran, G.N.; Santanam, M.S. Occurrence of chitin in the epicuticle of an arachnid Palmneus swammerdami. Nature 1955, 178, 557-558.

35. Kaya, M.; Seyyar, O.; Baran, T.; Erdoğan, S.; Kar, M. A physicochemical characterization of fully acetylated chitin structure isolated from two spider species: With new surface morphology. Int. J. Bol. Macromol. 2014, 65, 553-558.

36. Neville, A.C.; Parry, D.A.; Woodhead-Galloway, J. The chitin crystallite in arthropod cuticle. J. Cell Sci. 1976, 21, 73-82.

37. Liu, S.; Sun, J.; Yu, L.; Zhang, C.; Bi, J.; Zhu, F.; Qu, M.; Jiang, C.; Yang, Q. Extraction and characterization of chitin from the beetle Holotrichia parallela Motschulsky. Molecules 2012, 17, 4604-4611.

38. Merzendorfer, H. Insect chitin synthases: A review. J. Comp. Physiol. B Biochem. Syst. Environ. Physiol. 2006, 176, 1-15.

39. Glenn Richards, A. Studies on arthropod cutilce. III. The chitin of Limulus. Science 1949, 109, 591-592.

40. Giraud, M.-M. Fine structure of the chitin-protein system in the crab cuticle. Tissue Cell 1984, 16, 75-92. 
41. Giraud, M.-M.; Chanzy, H.; Vuong, R. Chitin crystals in arthropod cuticles revealed by diffraction contrast transmission electron microscopy. J. Struct. Biol. 1990, 103, 232-240.

42. Ando, Y.; Fukada, E.; Glimcher, M.J. Piezoelectricity of chitin in lobster shell and apodeme. Biorheology 1977, 14, 175-179.

43. Nieto Akosta, O.M.; Enriques Rodriguez, R.D.; Vitivskaya, G.A.; Elinov, N.P. Analysis of chitin from the skeleton of the spiny lobster Panulirus Argus. Appl. Biochem. Microbiol. 1978, 13, 604-607.

44. Fabritius, H.-O.; Sachs, C.; Triguero, P.R.; Raabe, D. Influence of structural principles on the mechanics of a biological fiber-based composite material with hierarchical organization: The exoskeleton of the lobster Homarus americanus. Adv. Mater. 2009, 21, 391-400.

45. Horst, M.N. The Biosynthesis of crustacean chitin by a microsomal enzyme from larval brine shrimp. J. Biol. Chem. 1981, 256, 1412-1419.

46. Rodde, R.; Einbu, A.; Varum, K.M. A seasonal study of the chemical composition and chitin quality of shrimp shells obtained from northern shrimp (Pandalus borealis). Carbohydr. Polym. 2008, 71, 388-393.

47. Nicol, S.; Hosie, G.W. Chitin production by krill. Biochem. Syst. Ecol. 1993, 21, 181-184.

48. Wang, Y.; Chang, Y.; Yu, L.; Zhang, C.; Xu, X.; Xue, Y.; Li, Z.; Xue, C. Crystalline structure and thermal property characterization of chitin from Antarctic krill (Euphausia superba). Carbohydr. Polym. 2013, 92, 90-97.

49. Stawski, D.; Rabiej, S.; Herczyńska, L.; Draczyński, Z. Thermogravimetric analysis of chitins of different origin. J. Therm. Anal. Calorim. 2008, 93, 489-494.

50. Wagner, G.P.; Lo, J.; Laine, R.; Almeder, M. Chitin in the epidermal cuticle of vertebrate (Paralipophorys trigloides, Blenniidae, Teleostei). Experientia 1993, 49, 317-319.

51. Ehrlich, H.; Maldonado, M.; Spindler, K.; Eckert, C.; Hanke, T.; Born, R.; Simon, P.; Heinemann, S.; Worch, H. First evidence of chitin as a component of the skeletal fibers of marine sponges. Part I. Verongidae (demospongia: Porifera). J. Exp. Zool. B 2007, 308, 347-356.

52. Ehrlich, H.; Krautter, M.; Hanke, T.; Simon, P.; Knieb, C.; Heinemann, S.; Worch, H. First evidence of the presence of chitin in skeletons of marine sponges. Part II. Glass sponges (Hexctinellida: Porifera). J. Exp. Zool. B 2007, 308, 473-483.

53. Brunner, E.; Ehrlich, H.; Schupp, P.; Hedrich, R.; Hunoldt, S.; Kammer, M.; Machill, S.; Paasch, S.; Bazhenov, V.V.; Kurek, D.V.; et al. Chitin-based scaffolds are an integral part of the skeleton of the marine demosponge Ianthella basta. J. Struct. Biol. 2009, 168, 539-547.

54. Rohde, S.; Schupp, P.J. Growth and regeneration of the elephant ear sponge Ianthella basta (Porifera). Hydrobiologia 2012, 687, 219-226.

55. Ehrlich, H.; Ilan, M.; Maldonado, M.; Muricy, G.; Bavestrello, G.; Kljajic, Z.; Carballo, J.L.; Schiaparelli, S.; Ereskovsky, A.; Schupp, P.; et al. Three-dimensional chitin-based scaffolds from Verongida sponges (Demospongiae: Porifera). Part I. Isolation and identification of chitin. Int. J. Bol. Macromol. 2010, 47, 132-140.

56. Cruz-Barraza, J.A.; Carballo, J.L.; Rocha-Olivares, A.; Ehrlich, H.; Hog, M. Integrative taxonomy and molecular phylogeny of genus Aplysina (Demospongiae: Verongida) from Mexican Pacific. PLoS One 2012, 7, doi:10.1371/journal.pone.0042049. 
57. Wysokowski, M.; Bazhenov, V.V.; Tsurkan, M.V.; Galli, R.; Stelling, A.L.; Stöcker, H.; Kaiser, S.; Niederschlag, E.; Gärtner, G.; Behm, T.; et al. Isolation and identification of chitin in three-dimensional skeleton of Aplysina. fistularis marine sponge. Int. J. Biol. Macromol. 2013, 62, 94-100.

58. Ehrlich, H.; Kaluzhnaya, O.V.; Tsurkan, M.V.; Ereskovsky, A.; Tabachnick, K.R.; Ilan, M.; Stelling, A.; Galli, R.; Petrova, O.V.; Nekipelov, S.V.; et al. First report on chitinous holdfast in sponges (Porifera). Proc. R. Soc. B 2013, 280, doi:10.1098/rspb.2013.0339.

59. Ehrlich, H.; Kaluzhnaya, O.V.; Brunner, E.; Tsurkan, M.V.; Ereskovsky, A.; Ilan, M.; Tabachnick, K.R.; Bazhenov, V.V.; Paasch, S.; Kammer, M.; et al. Identification and first insights into the structure and biosynthesis of chitin from the freshwater sponge Spongilla lacustris. J. Struct. Biol. 2013, 183, 474-483.

60. Ehrlich, H.; Rigby, J.K.; Botting, J.P.; Tsurkan, M.; Werner, C.; Schwille, P.; Petrasek, Z.; Pisera, A.; Simon, P.; Sivkov, V.; et al. Discovery of 505-million-year old chitin in the basal demosponge Vauxia gracilenta. Sci. Rep. 2013, 3, 3497.

61. Stankiewicz, B.A. Preservation of chitin in 25-million-year-old fossils. Science 1997, 276, 1541-1543.

62. Wysokowski, M.; Zatoń, M.; Bazhenov, V.V.; Behm, T.; Ehrlich, A.; Stelling, A.L.; Hog, M.; Ehrlich, H. Identification of chitin in 200-million-year-old gastropod egg capsules. Paleobiology 2014, 40, 529-540.

63. Ehrlich, H. Biomimetic potential of chitin-based composite biomaterials of poriferan origin. In Biomimetic Biomaterials: Structure and Aplications; Ruys, A.J., Ed.; Woodhead Publishing Ltd.: Cambridge, UK, 2013; pp. 47-67.

64. Ehrlich, H.; Steck, E.; Ilan, M.; Maldonado, M.; Muricy, G.; Bavestrello, G.; Kljajic, Z.; Carballo, J.L.; Schiaparelli, S.; Ereskovsky, A.; et al. Three-dimensional chitin-based scaffolds from Verongida sponges (Demospongiae: Porifera). Part II: Biomimetic potential and applications. Int. J. Biol. Macromol. 2010, 47, 141-145.

65. Rogulska, O.Y.; Mutsenko, V.V.; Revenko, E.B.; Petrenko, Y.A.; Ehrlich, H.; Petrenko, A.Y. Culture and differentiation of human adipose tissue mesenchymal stromal cells within carriers based on sea sponge chitin skeletons. Stem Cell Day 2013, 23, 267-270.

66. Steck, E.; Burkhardt, M.; Ehrlich, H.; Richter, W. Discrimination between cells of murine and human origin in xenotransplants by species specific genomic in situ hybridization. Xenotransplantaiton 2010, 17, 153-159.

67. Ehrlich, H. Chitin and collagen as universal and alternative templates in biomineralization. Int. Geol. Rev. 2010, 52, 661-699.

68. Ehrlich, H.; Simon, P.; Carrillo-Cabrera, W.; Bazhenov, V.V.; Botting, J.P.; Ilan, M.; Ereskovsky, A.V.; Muricy, G.; Worch, H.; Mensch, A.; et al. Insights into chemistry of biological materials: Newly discovered silica-aragonite-chitin biocomposites in demosponges. Chem. Mater. 2010, 22, 1462-1471.

69. Khoushab, F.; Yamabhai, M. Chitin research revisited. Mar. Drugs 2010, 8, 1988-2012.

70. Rinaudo, M. Chitin and chitosan: Properties and applications. Prog. Polym. Sci. 2006, 31, $603-632$. 
71. Pillai, C.K.S.; Paul, W.; Sharma, C.P. Chitin and chitosan polymers: Chemistry, solubility and fiber formation. Prog. Polym. Sci. 2009, 34, 641-678.

72. Wan, A.C.A.; Tai, B.C.U. Chitin-A promising biomaterial for tissue engineering and stem cell technologies. Biotechnol. Adv. 2013, 31, 1776-1785.

73. Bhatnagar, A.; Sillanpää, M. Applications of chitin- and chitosan-derivatives for the detoxification of water and wastewater-A short review. Adv. Colloid Interface Sci. 2009, 152, 26-38.

74. Westholm, L.J.; Repo, E.; Sillanpää, M. Filter materials for metal removal from mine drainage-A review. Environ. Sci. Pollut. Res. Int. 2014, 21, 9109-9128.

75. Kousalya, G.N.; Gandhi, M.R.; Viswanathan, N.; Meenakshi, S. Preparation and metal uptake studies of modified forms of chitin. Int. J. Bol. Macromol. 2010, 47, 583-589.

76. Krajewska, B. Application of chitin- and chitosan-based materials for enzyme immobilizations: A review. Enzyme Microb. Technol. 2004, 35, 126-139.

77. Anitha, A.; Sowmya, S.; Kumar, P.; Deepthi, S.; Chennazhi, K.P.; Ehrlich, H.; Tsurkan, M.; Jayakumar, R. Chitin and chitosan in selected biomedical applications. Prog. Polym. Sci. 2014, 39, 1644-1667.

78. Jayakumar, R.; Chennazhi, K.P.; Srinivasan, S.; Nair, S.V.; Furuike, T.; Tamura, H. Chitin scaffolds in tissue engineering. Int. J. Mol. Sci. 2011, 12, 1876-1887.

79. Hajji, S.; Younes, I.; Ghorbel-Bellaaj, O.; Hajji, R.; Rinaudo, M.; Nasri, M.; Jellouli, K. Structural differences between chitin and chitosan extracted from three marine sources. Int. J. Bol. Macromol. 2014, 65, 298-306.

80. Focher, B.; Naggi, A.; Torri, G. Structural differences between chitin polymorphs and their precipitates from solutions-Evidence from CP-MAS 13 C-NMR, FT-IR and FT-Raman spectroscopy. Carbohydr. Polym. 1992, 17, 97-102.

81. Sikorski, P.; Hori, R.; Wada, M. Revisit of $\alpha$-chitin crystal structure using high resolution X-ray diffraction data. Biomacromolecules 2009, 10, 1100-1105.

82. Darmon, S.; Rudall, K. Infra-red and X-ray studies of chitin. Discuss. Faraday Soc. 1950, 9, 253-260.

83. Rudall, K.; Kenchington, W. The chitin system. Biol. Rev. 1973, 49, 597-636.

84. Jang, M.-K.; Kong, B.-G.; Jeong, Y.-I.; Lee, C.H.; Nah, J.-W. Physicochemical characterization of $\alpha$-chitin, $\beta$-chitin, and $\gamma$-chitin separated from natural resources. J. Polym. Sci. A Polym. Chem. 2004, 42, 3423-3432.

85. Calström, D. The crystal structure of $\alpha$-chitin (poly- $N$-acetyl-D-glucosamine). J. Biophys. Biochem. Cytol. 1957, 3, 669-683.

86. Minke, R.; Blackwell, J. The structure of $\alpha$-chitin. J. Mol. Biol. 1978, 120, 167-181.

87. Ogawa, Y.; Kimura, S.; Wada, M.; Kuga, S. Crystal analysis and high-resolution imaging of microfibrillar $\alpha$-chitin from Phaecystis. J. Struct. Biol. 2010, 171, 111-116.

88. Petrov, M.; Lymperakis, L.; Friák, M.; Neugebauer, J. Ab initio based conformational study of the crystalline $\alpha$-chitin. Biopolymers 2012, 99, 22-34.

89. Dweltz, N.E. The structure of $\beta$-chitin. Biochim. Biophys. Acta 1961, 51, 283-294.

90. Blackwell, J. Structure of $\beta$-chitin or parallel chain system of poly- $\beta-(1-4)-\mathrm{N}$-acetyl-D-glucosamine. Biopolymers 1969, 7, 281-298. 
91. Salmon, S.; Hudson, S.M. Crystal morphology, biosynthesis, and physical assembly of cellulose, chitin and chitosan. J. Macromol. Sci. C 1997, 37, 199-276.

92. Muzzarelli, R.A.A.; El Mehtedi, M.; Mattioli-Belmonte, M. Emerging biomedical application of nano-chitins and nano-chitosans obtained via advanced eco-friendly technologies from marine resources. Mar. Drugs 2014, 12, 5468-5502.

93. Saito, Y.; Okano, T.; Gaill, F.; Chanzy, H.; Putaux, J.L. Structural data on the intra-crystalline swelling of beta-chitin. Int. J. Biol. Macromol. 2000, 28, 81-88.

94. Kobayashi, K.; Kimura, S.; Togawa, E.; Wada, M. Crystal transition between hydrate and anhydrous $\beta$-chitin monitored by synchrotron X-ray fiber diffraction. Carbohydr. Polym. 2010, 79, $882-889$.

95. Sawada, D.; Ogawa, Y.; Kimura, S.; Nishiyama, Y.; Langan, P.; Masahisa, W. Solid-solvent molecular interactions observed in crystal structures of $\beta$-chitin complexes. Cellulose 2014, 21 , 1007-1014.

96. Sawada, D.; Nishiyama, Y.; Langan, P.; Forsyth, V.T.; Kimura, S. Water in crystalline fibers of dehydrate $\beta$-chitin results in unexpected absence of intramolecular hydrogen bonding. PLoS One 2012, 7, doi:10.1371/journal.pone.0039376.

97. Grunenfelder, L.K.; Suksangpanya, N.; Salinas, C.; Milliron, G.; Yaraghi, N.; Herrera, S.; Evans-Lutterodt, K.; Nutt, S.R.; Zavattieri, P.; Kisailus, D. Bio-inspired impact-resistant composites. Acta Biomater. 2014, 10, 3997-4008.

98. Raabe, D.; Al-Sawalmih, A.; Yi, S.B.; Fabritius, H. Preferred crystallographic texture of $\alpha$-chitin as a microscopic and macroscopic design principle of the exoskeleton of the lobster Homarus americanus. Acta Biomater. 2007, 3, 882-895.

99. Yang, F.-C.; Peters, R.D.; Dies, H.; Rheinstädter, M.C. Hierarchical, self-similar structure in native squid pen. Soft Matter 2014, 10, 5541-5549.

100. Abe, M.; Takahashi, M.; Tokura, S.; Tamura, H.; Nagano, A. Cartilage-scaffold composites produced by bioresorbable $\beta$-chitin sponge with cultured rabbit chondrocytes. Tissue Eng. 2004, 10, 585-594.

101. Okamoto, Y.; Minami, S.; Matsuhashi, A.; Sashiwa, H.; Saimoto, H.; Shigemasa, Y.; Tanigawa, T.; Tanaka, Y.; Tokura, S. Application of polymeric $N$-acetyl-D-glucosamine (chitin) to veterinary practice. J. Vet. Med. Sci. 1993, 55,743-747.

102. Shigemasa, Y.; Minami, S. Application of chitin and chitosan for biomaterials. Biotechnol. Genet. Eng. Rev. 1996, 13, 383-420.

103. Duan, B.; Gao, H.; He, M.; Zhang, L. Hydrophobic modification of surface of chitin sponges for highly effective separation of oil. ACS Appl. Mater. Interfaces 2014, 6, 19933-19942.

104. Jaworska, M.M.; Kozlecki, T.; Gorak, A. Review of the application of ionic liquids as solvents for chitin. J. Polym. Eng. 2012, 32, 67-69.

105. Barber, P.S.; Griggs, C.S.; Bonner, J.R.; Rogers, R.D. Electrospinning of chitin nanofibers directly from an ionic liquid extract of shrimp shells. Green Chem. 2013, 15, 601-607.

106. Qin, Y.; Lu, X.; Sun, N.; Rogers, R.D. Dissolution or extraction of crustacean shells using ionic liquids to obtain high molecular weight purified chitin and direct production of chitin films and fibers. Green Chem. 2010, 12, 968-971. 
107. Sharma, M.; Chandrakant, M.; Mondal, D.; Prasad, K. Dissolution of $\alpha$-chitin in deep eutectic solvents. RSC Adv. 2013, 3, 18149-18155.

108. Ifuku, S. Chitin and chitosan nanofibers: Preparation and chemical modifications. Molecules 2014, 19, 18367-18380.

109. Ifuku, S.; Nogi, M.; Abe, K.; Yoshoka, M.; Morimoto, M.; Saimoto, H.; Yano, H. Simple preparation method of chitin nanofibers with a uniform width of 10-20 nm from prawn shell under neutral conditions. Carbohydr. Polym. 2011, 84, 762-764.

110. Ifuku, S.; Saimoto, H. Chitin nanofibers: Preparations, modifications, and applications. Nanoscale 2012, 4, 3308-3318.

111. Lu, Y.; Sun, Q.; She, X.; Xia, Y.; Liu, Y.; Li, J.; Yang, D. Fabrication and characterization of $\alpha$-chitin nanofibers and highly transparent hitin films by pulsed ultrasonication. Carbohydr. Polym.2013, 98, 1497-1504.

112. Bentov, S.; Zaslansky, P.; Al-Sawalmih, A.; Masic, A.; Fratzl, P.; Sagi, A.; Berman, A.; Aichmayer, B. Enamel-like apatite crown covering amorphous mineral in a crayfish mandible. Nat. Commun. 2012, 3, doi:10.1038/ncomms 1839.

113. Grunenfelder, L.; Herrera, S.; Kisailus, D. Crustacean-derived biomimetic components and nanostructured composites. Small 2014, 10, 3207-3232.

114. Wysokowski, M.; Behm, T.; Born, R.; Bazhenov, V.V.; Meißner, H.; Richter, G.; Szwarc-Rzepka, K.; Makarova, A.; Vyalikh, D.; Schupp, P.; et al. Preparation of chitin-silica composites by in vitro silicification of two-dimensional Ianthella basta demosponge chitinous scaffolds under modified Stöber conditions. Mater. Sci. Eng. C 2013, 33, 3935-3941.

115. Michels, J.; Vogt, J.; Gorb, S.N. Tools for crushing diatoms-Opal teeth in copepod feature a rubber-like bearing composted of resilin. Sci. Rep. 2012, 2, 465.

116. Politi, Y.; Priewasser, M.; Pippel, E.; Zaslansky, P.; Hartman, J.; Siegel, S.; Li, C.; Barth, F.G.; Fratzl, P. A spider's fang: How to design an injection needle using chitin-based composite material. Adv. Funct. Mater. 2012, 22, 2519-2528.

117. Fernandez, J.G.; Ingber, D.E. Bioinspired chitinous material solutions for environmental sustainability and medicine. Adv. Funct. Mater. 2013, 23, 4454-4466.

118. Yousof, N.L.B.M.; Lim, L.Y.; Khor, E. Flexible chitin films: Structural studies. Carbohydr. Res. 2004, 339, 2701-2711.

119. Duan, B.; Chang, C.; Ding, B.; Cai, J.; Xu, M.; Feng, S.; Ren, J.; Shi, X.; Du, Y.; Zhang, L. High strength films with gas-barrier fabricated from chitin solution dissolved at low temperature. J. Mater. Chem. A 2013, 1, 1867-1874.

120. Hassanzadeh, P.; Sun, W.; de Silva, J.P.; Jin, J.; Makhnejia, K.; Cross, G.L.W.; Rolandi, M. Mechanical properties of self-assembled chitin nanofiber networks. J. Mater. Chem. B 2014, 2 , 2461-2466.

121. Vincent, J.F.W.; Wegst, U.G.K. Design and mechanical properties of insect cuticle. Arth. Struct. Dev. 2004, 187-199.

122. Ifuku, S.; Morooka, S.; Nakagato, A.N.; Morimoto, M.; Saimoto, H. Preparation and characterization of optically transparent chitin nanofiber/(meth)acrylic resin composites. Green Chem. 2011, 13, 1708-1711. 
123. Kim, J.Y.; Chang, S.H.; Jo, N.J. Synthesis and properties of biodegradable chitin-graf-poly(L-lactide) copolymers. Polym. Int. 2002, 51, 1123-1128.

124. Chen, B.; Sun, K.; Ren, T. Mechanical and viscoelastic properties of chitin fiber reinforced poly(E-caprolactone). Eur. Polym. J. 2005, 41, 453-457.

125. Jayakumar, R.; Tamura, H. Synthesis, characterization and thermal properties of chitin- $g$-poly( $\gamma$-caprolactone) copolymers by using chitin gel. Int. J. Biol. Macromol. 2008, 43, 32-36.

126. Bischof, J.C.; He, X. Thermal stability of proteins. Ann. N. Y. Acad. Sci. 2005, 1066, 12-33.

127. Bershtein, V.A.; Egorov, V.M.; Egorova, L.M.; Ryzhov, V.A. The role of thermal analysis in revealing the common molecular nature of transitions in polymers. Thermochim. Acta 1994, 238, 41-73.

128. Kittur, F.S.; Harish Prashanth, K.V.; Udaya Sankar, K.; Tharanathan, R.N. Characterization of chitin, chitosan and their carboxymethyl derivatives by differential scanning calorimetry. Carbohydr. Polym. 2002, 49, 185-193.

129. Köll, P.; Metzger, J. Nachweis von acetamid beim thermischen abbau von chitin. Z. Lebensm. Unters. Forsch. 1979, 113, 111-113. (In German)

130. Köll, P.; Borchers, G.; Metzger, J.O. Thermal degradation of chitin and cellulose. J. Anal. Appl. Pyrolysis 1991, 19, 119-129.

131. Wanjun, T.; Cunxin, W.; Donghua, C. Kinetic studies on the pyrolysis of chitin and chitosan. Polym. Degrad. Stable 2005, 87, 389-394.

132. Friedman, H.L. Kinetics of thermal degradation of char-forming plastics from thermogravimetry. Application to a phenolic plastic. J. Polym. Sci. C 2007, 6, 183-195.

133. Stolarek, P.; Ledakowicz, S. Pyrolysis kinetics of chitin by non-isothermal thermogravimetry. Thermochim. Acta 2005, 433, 200-208.

134. Nam, Y.S.; Park, W.H.; Ihm, D.; Hudson, S.M. Effect of the degree of deacetylation on the thermal decomposition of chitin and chitosan nanofibers. Carbohydr. Polym. 2010, 80, 291-295.

135. Georgieva, V.; Zvezdova, D.; Vlaev, L. Non-isothermal kinetics of thermal degradation of chitin. J. Therm. Anal. Calorim. 2013, 111, 763-771.

136. Cardenas, G.; Etamal, J.; Tagle, L. Thermogravimetric studies of chitin derivatives I. Int. J. Polym. Mater. Polym. Biomater. 1993, 21, 137-146.

137. Ehrlich, H.; Simon, P.; Motylenko, M.; Wysokowski, M.; Bazhenov, V.V.; Galli, R.; Stelling, A.L.; Stawski, D.; Ilan, M.; Stöcker, H.; et al. Extreme biomimetics: Formation of zirconium dioxide nanophase using chitinous scaffolds under hydrothermal conditions. J. Mater. Chem. B 2013, 1, 5092-5099.

138. Kaya, M.; Erdogan, S.; Mol, A.; Baran, T. Comparison of chitin structures isolated from seven Orthoptera species. Int. J. Bol. Macromol. 2014, 72, 797-805.

139. Kaya, M.; Karaarslan, M.; Baran, T.; Can, E.; Ekemen, G.; Bitim, B.; Duman, F. The quick extraction of chitin from an epizoic crustacean species (Chelonibia patula). Nat. Prod. Res. 2014, 28, 2186-2190.

140. Ruiz-Hitzky, E.; Darder, M.; Aranda, P.; Ariga, K. Advances in biomimetic and nanostructured biohybrid materials. Adv. Mater. 2010, 22, 323-336.

141. Li, Y.; Chiu, C.-Y.; Huang, Y. Biomimetic synthesis of inorganic materials and their applications. Pure Appl. Chem. 2010, 83, 111-125. 
142. Sanchez, C.; Arribart, H.; Guille, M.M.G. Biomimetism and bioinspiration as tools for the design of innovative materials and systems. Nat. Mater. 2005, 4, 277-288.

143. Xu, A.-W.; Ma, Y.; Cölfen, H. Biomimetic mineralization. J. Mater. Chem. 2007, 17, 415-449.

144. Shin, H.; Jo, S.; Mikos, A.G. Biomimetic materials for tissue engineering. Biomaterials 2003, 24, 4353-4364.

145. Liu, C.; Yang, D.; Jiao, Y.; Tian, Y.; Wang, Y.; Jiang, Z. Biomimetic synthesis of $\mathrm{TiO}_{2}-\mathrm{SiO}_{2}-\mathrm{Ag}$ nanocomposites with enhanced visible-light photocatalytic activity. ACS Appl. Mater. Interfaces 2013, 5, 3824-3832.

146. Andre, R.; Tahir, M.N.; Natalio, F.; Tremel, W. Bioinspired synthesis of multifunctional inorganic and bio-organic hybrid materials. FEBS J. 2012, 279, 1737-1749.

147. Yan, X.; Blacklock, J.; Li, J.; Möhwald, H. One-pot synthesis of polypeptide—Gold nanoconjugates for in vitro gene transfection. ACS Nano 2012, 6, 111-117.

148. Yan, X.; Li, J.; Möhwald, H. Templating assembly of multifunctional hybrid colloidal spheres. Adv. Mater. 2012, 24, 2663-2667.

149. Li, N.; Niu, L.; Qi, Y.; Yiu, C.K.Y.; Ryou, H.; Arola, D.D.; Chen, J.; Pashley, D.H.; Tay, F.R. Subtleties of biomineralisation revealed by manipulation of the eggshell membrane. Biomaterials 2011, 32, 8743-8752.

150. Canabady-Rochelle, L.L.S.; Belton, D.J.; Deschaume, O.; Currie, H.A.; Kaplan, D.L.; Perry, C.C. Bioinspired silicification of silica-binding peptide-silk protein chimeras: Comparison of chemically and genetically produced proteins. Biomacromolecules 2012, 13, 683-690.

151. Rodríguez, F.; Glawe, D.D.; Naik, R.R.; Hallinan, K.P.; Stone, M.O. Study of the chemical and physical influences upon in vitro peptide-mediated silica formation. Biomacromolecules 2004, 5, 261-265.

152. Patwardhan, S.V.; Maheshwari, R.; Mukherjee, N.; Kiick, K.L.; Clarson, S.J. Conformation and assembly of polypeptide scaffolds in templating the synthesis of silica: An example of a polylysine macromolecular "switch". Biomacromolecules 2006, 7, 491-497.

153. Zhong, C.; Chu, C.C. Biomimetic mineralization of acid polysaccharide-based hydrogels: Towards porous 3-dimensional bone-like biocomposites. J. Mater. Chem. 2012, 22, 6080-6087.

154. Munro, N.H.; McGrath, K.M. Biomimetic mineralisation of polymeric scaffolds using a combined soaking approach: Adaptation with various mineral salts. Dalt. Trans. 2011, 40, 9269-9275.

155. Munro, N.H.; Green, D.W.; Dangerfield, A.; McGrath, K.M. Biomimetic mineralisation of polymeric scaffolds using a combined soaking and Kitano approach. Dalt. Trans. 2011, 40, 9259-9268.

156. Munro, N.H.; Green, D.W.; McGrath, K.M. In situ continuous growth formation of synthetic biominerals. Chem. Commun. 2013, 49, 3407-3409.

157. Spinde, K.; Kammer, M.; Freyer, K.; Ehrlich, H.; Vournakis, J.N.; Brunner, E. Biomimetic silicification of fibrous chitin from diatoms. Chem. Mater. 2011, 23, 2973-2978.

158. Tseng, Y.; Lin, H.; Liu, M. Biomimetic synthesis of nacrelike faceted mesocrystals of ZnO-gelatin composite. J. Phys. Chem. C 2009, 113, 18053-18061. 
159. Wysokowski, M.; Motylenko, M.; Stöcker, H.; Bazhenov, V.V.; Langer, E.; Dobrowolska, A.; Czaczyk, K.; Galli, R.; Stelling, A.L.; Behm, T.; et al. An extreme biomimetic approach: Hydrothermal synthesis of $\beta$-chitin/ZnO nanostructured composites. J. Mater. Chem. B 2013, 1 , 6469-6476.

160. Wysokowski, M.; Motylenko, M.; Bazhenov, V.V.; Stawski, D.; Petrenko, I.; Ehrlich, A.; Behm, T.; Kljajic, Z.; Stelling, A.L.; Jesionowski, T.; et al. Poriferan chitin as a template for hydrothermal zirconia deposition. Front. Mater. Sci. 2013, 7, 248-260.

161. Wysokowski, M.; Piasecki, A.; Bazhenov, V.V.; Paukszta, D.; Born, R.; Petrenko, I.; Jesionowski, T. Poriferan chitin as the scaffold for nanosilica deposition under hydrothermal synthesis conditions. J. Chitin Chitosan Sci. 2013, 1, 26-33.

162. Thornburg, C.C.; Zabriskie, T.M.; Mcphail, K.L. Deep-sea hydrothermal vents: Potential hot spots for natural products discovery? J. Nat. Prod. 2010, 73, 489-499.

163. Jannasch, H.; Mottl, M. Geomicrobiology of deep-sea hydrothermal vents. Science 1985, 229, $717-725$.

164. Li, J.; Zhou, H.; Peng, X.; Wu, Z.; Chen, S.; Fang, J. Microbial diversity and biomineralization in low-temperature hydrothermal iron-silica-rich precipitates of the Lau Basin hydrothermal field. FEMS Microbiol. Ecol. 2012, 81, 205-216.

165. Emerson, D.; Rentz, J.A.; Lilburn, T.G.; Davis, R.E.; Aldrich, H.; Chan, C.; Moyer, C.L. A novel lineage of proteobacteria involved in formation of marine Fe-oxidizing microbial mat communities. PLoS One 2007, 2, doi:10.1371/journal.pone.0000667.

166. Reysenbach, A.-L.; Liu, Y.; Banta, A.B.; Beveridge, T.J.; Kirshtein, J.D.; Schouten, S.; Tivey, M.K.; von Damm, K.L.; Voytek, M.A. A ubiquitous thermoacidophilic archaeon from deep-sea hydrothermal vents. Nature 2006, 442, 444-447.

167. Islas, S.; Velasco, A.M.; Becerra, A.; Delaye, L.; Lazcano, A. Hyperthermophily and the origin and earliest evolution of life. Int. Microbiol. 2003, 6, 87-94.

168. Ehrlich, H. Biological Materials of Marine Origin; Springer Science + Business Media B.V.: Dordrecht, The Netherlands, 2010.

169. Zbinden, M.; Le Bris, N.; Compère, P.; Martinez, I.; Guyot, F.; Gaill, F. Mineralogical gradients associated with alvinellids at deep-sea hydrothermal vents. Deep Sea Res. I Oceanogr. Res. Papers 2003, 50, 269-280.

170. Nidhin, M.; Sreeram, K.J.; Nair, B.U. Polysaccharide films as templates in the synthesis of hematite nanostructures with special properties. Appl. Surf. Sci. 2012, 258, 5179-5184.

171. Ercole, C.; Cacchio, P.; Botta, A.L.; Centi, V.; Lepidi, A. Bacterially induced mineralization of calcium carbonate: The role of exopolysaccharides and capsular polysaccharides. Microsc. Microanal. 2007, 13, 42-50.

172. Chan, C.S.; Fakra, S.C.; Edwards, D.C.; Emerson, D.; Banfield, J.F. Iron oxyhydroxide mineralization on microbial extracellular polysaccharides. Geochim. Cosmochim. Acta 2009, 73, 3807-3818.

173. Hedrich, R.; Machill, S.; Brunner, E. Biomineralization in diatoms-phosphorylated saccharides are part of Stephanopyxis turris biosilica. Carbohydr. Res. 2013, 365, 52-60.

174. Gilbert, P.U.P.A.; Abrecht, M.; Frazer, B.H. The Organic-mineral interface in biominerals. Rev. Mineral. Geochem. 2005, 59, 157-185. 
175. Preat, A.; Mamet, B.; de Ridder, C.; Boulvain, F.; Gillan, D. Iron bacterial and fungal mats, Bajocian stratotype (Mid-Jurassic, northern Normandy, France). Sediment. Geol. 2000, 137, 107-126.

176. Djurišić, A.; Xi, Y.Y.; Hsu, Y.F.; Chan, W.K. Hydrothermal synthesis of nanostructures. Recent Pat. Nanotechnol. 2007, 1, 121-128.

177. Riman, R.; Suchanek, W.; Lencka, M. Hydrothermal crystallization of ceramics. Ann. Chim. Sci. Matér. 2002, 27, 15-36.

178. Byrappa, K.; Adschiri, T. Hydrothermal technology for nanotechnology. Prog. Cryst. Growth Charact. Mater. 2007, 53, 117-166.

179. Rabenau, B.A. The role of hydrothermal synthesis in preparative chemistry. Angew. Chem. Int. Ed. 1985, 24, 1026-1040.

180. Yoshimura, M.; Byrappa, K. Hydrothermal processing of materials: Past, present and future. J. Mater. Sci. 2007, 43, 2085-2103.

181. Feng, S.; Xu, R. New materials in hydrothermal synthesis. Acc. Chem. Res. 2001, 34, 239-247.

182. Djurišić, A.; Chen, X.Y.; Leung, Y.H. Recent progress in hydrothermal synthesis of zinc oxide nanomaterials. Recent Pat. Nanotechnol. 2012, 6, 124-134.

183. Namratha, K.; Byrappa, K. Novel solution routes of synthesis of metal oxide and hybrid metal oxide nanocrystals. Prog. Cryst. Growth Charact. Mater. 2012, 58, 14-42.

184. Aida, T.M.; Oshima, K.; Abe, C.; Maruta, R.; Iguchi, M.; Watanabe, M.; Smith, R.L. Dissolution of mechanically milled chitin in high temperature water. Carbohydr. Polym. 2014, 106, 172-178.

185. Schleuter, D.; Günther, A.; Paasch, S.; Ehrlich, H.; Kljajić, Z.; Hanke, T.; Bernhard, G.; Brunner, E. Chitin-based renewable materials from marine sponges for uranium adsorption. Carbohydr. Polym. 2013, 92, 712-718.

186. Ogasawara, W.; Shenton, W.; Davis, S.A.; Mann, S. Template mineralization of ordered macroporous chitin-silica composites using a cuttlebone-derived organic matrix. Chem. Mater. 2000, 12, 2835-2837.

187. Peter, M.; Sudheesh Kumar, P.T.; Binulal, N.S.; Nair, S.V.; Tamura, H.; Jayakumar, R. Development of novel $\alpha$-chitin/nanobioactive glass ceramic composite scaffolds for tissue engineering applications. Carbohydr. Polym. 2009, 78, 926-931.

188. Copello, G.J.; Mebert, A.M.; Raineri, M.; Pesenti, M.P.; Diaz, L.E. Removal of dyes from water using chitosan hydrogel $/ \mathrm{SiO}_{2}$ and chitin hydrogel $/ \mathrm{SiO}_{2}$ hybrid materials obtained by the sol-gel method. J. Hazard. Mater. 2011, 186, 932-939.

189. Hamid, R.A.-S.; Al-Akayleh, F.; Shubair, M.; Rashid, I.; Al Remawi, M.; Badwan, A. Evaluation of three chitin metal silicate co-precipitates as a potential multifunctional single excipient in tablet formulations. Mar. Drugs 2010, 8, 1699-1715.

190. Song, D.; Breedveld, V.; Deng, Y. Rheological study of self-crosslinking and co-crosslinking of ammonium zirconium carbonate and starch in aqueous solutions. J. Appl. Polym. Sci. 2011, 122, 1019-1029.

191. Mikkonen, K.S.; Schmidt, J.; Vesterinen, A.-H.; Tenkanen, M. Crosslinking with ammonium zirconium carbonate improves the formation and properties of spruce galactoglucomannan films. J. Mater. Sci. 2013, 48, 4205-4213.

192. Zong, S.; Cao, Y.; Zhou, Y.; Ju, H. Hydrogen peroxide biosensor based on hemoglobin modified zirconia nanoparticles-grafted collagen matrix. Anal. Chim. Acta 2007, 582, 361-366. 
193. Hristovski, K.D.; Westerhoff, P.K.; Crittenden, J.C.; Olson, L.W. Arsenate removal by nanostructured $\mathrm{ZrO}_{2}$ spheres. Environ. Sci. Technol. 2008, 42, 3786-3790.

194. Da Sacco, L.; Masotti, A. Chitin and chitosan as multipurpose natural polymers for groundwater arsenic removal and $\mathrm{As}_{2} \mathrm{O}_{3}$ delivery in tumor therapy. Mar. Drugs 2010, 8, 1518-1525.

195. Piconi, C.; Maccauro, G. Zirconia as a ceramic biomaterial. Biomaterials 1999, 20, 1-25.

196. Manicone, P.F.; Rossi Iommetti, P.; Raffaelli, L. An overview of zirconia ceramics: Basic properties and clinical applications. J. Dent. 2007, 35, 819-826.

197. Tang, S.; Huang, X.; Chen, X.; Zheng, N. Hollow mesoporous zirconia nanocapsules for drug delivery. Adv. Funct. Mater. 2010, 20, 2442-2447.

198. Ehrlich, H.; Brunner, E.; Richter, W.; Ilan, M.; Schupp, P. Two or Three-Dimensional Cleaned Chitin Skeleton of Dictyoceratid Sponges, Method for the Production and Use Thereof. WO2011023531 A2, 3 March 2011.

199. Nata, I.F.; Wang, S.S.-S.; Wu, T.-M.; Lee, C.-K. $\beta$-Chitin nanofibrils for self-sustaining hydrogels preparation via hydrothermal treatment. Carbohydr. Polym. 2012, 90, 1509-1514.

(C) 2015 by the authors; licensee MDPI, Basel, Switzerland. This article is an open access article distributed under the terms and conditions of the Creative Commons Attribution license (http://creativecommons.org/licenses/by/4.0/). 